\title{
The collapse of Space building
}

\author{
B. CAICEDO*, E. ALONSO $†$, C. MENDOZA $\$$ and J. ALCOVERRO†
}

\begin{abstract}
On 12 October 2013, the 24-storey high 'Space' building collapsed in Medellín, Colombia. The building had a reinforced concrete structure founded on large-diameter piles with enlarged bases. During and after construction the building exhibited structural problems and excessive settlements of some piles. Because of the evidence of structural damage, the building was evacuated on 11 October 2013, 1 day before the collapse. Isolated large-diameter piles excavated in a firm, high-plasticity saprolitic residual clay, supported building columns. Building collapse was triggered by a significant increase of the vertical load transmitted by some columns, which, in turn, is explained by widely different settlements experienced by neighbouring piles and the resulting loading transfer mechanisms. The first part of the paper presents the results of the field exploration and laboratory tests, as well as the structural and architectural layout, including the construction process and other forensic aspects that could influence the collapse of the structure. Afterwards, the joint structure-foundation-soil numerical model developed and its predictions are described. Matching the records of pile settlements, measured during construction and afterwards until building collapse, with model predictions allowed the validation of the model. The causes that triggered the collapse were identified and some other lessons were learned.
\end{abstract}

KEYWORDS: bearing capacity; design; footings/foundations; numerical modelling

\section{INTRODUCTION}

This paper describes the geotechnical and structural conditions leading to the collapse of Tower 6 of the Space building located in Medellín, Colombia. The building had six connected towers (Fig. 1) of increasing height, which were built sequentially. The towers were occupied, one by one, after finalising their construction. Reinforced concrete beams, connecting the towers, provided a structural continuity to the entire building complex.

Tower 6, the tallest, was completed on 25 April 2013; it had 24 floors. Tower 6 suffered from excessive settlements and structural problems during and after construction. Serious damage observed in columns located in the lower floors of Tower 6 prompted its evacuation 1 day before its collapse on 12 October 2013 (Fig. 2). Emergency reinforcement was attempted immediately after evacuation. This did not succeed and the working team (12 persons) died during the collapse of the building.

The structure and pile foundation of the building are first described. Settlements of pile caps were measured during construction and the time records allowed the interpretation of the differential settlements experienced by the tower and their impact on structural integrity.

The forensic study includes a soil characterisation performed after the collapse of the building. This part of the study was carried out by means of field and laboratory tests, as well as a large-diameter exploration well. The paper also

Manuscript received 21 October 2017; revised manuscript accepted 24 April 2018. Published online ahead of print 30 May 2018.

Discussion on this paper closes on 1 August 2019, for further details see p. ii.

* Department of Civil and Environmental Engineering, Universidad de Los Andes, Bogotá, Colombia (Orcid:0000-0003-4344-0914).

$\dagger$ Civil Engineering School, Geotechnical Engineering and Geosciences Division, Universitat Politècnica de Catalunya, Barcelona, Spain.

† Civil Engineering, Universidad Nacional de Colombia Sede Manizales, Manizales, Caldas, Colombia. describes the coupled numerical model developed. This includes the structure, the pile foundations and the physical and mechanical properties of the soil. A useful benchmark to validate the model developed is provided by the settlement records of the pile caps. The discussion of causes leading to building collapse relies on the insight provided by the model calculations.

The collapse of Space Tower 6 is a rare case of a massive collapse of a tall building, ultimately caused by the construction defects of a single pile, by a specific pile construction practice and by the delay in adopting compensating measures during construction.

\section{STRUCTURE AND FOUNDATION OF TOWER 6}

The structure of Tower 6 essentially consists of 24 continuous concrete slabs of variable thickness supported by rectangular columns spaced $7.5 \mathrm{~m} \times 8.3 \mathrm{~m}$ in the direction of minimum and maximum dimensions of the rectangular tower.

The geometry of the reinforced concrete floors is shown in Fig. 3. The plot provides a planar view of the slab in the area supported by pillars R3, S3, R5, S5; see also Fig. 4. Fig. 3 shows two cross-sections describing the trapezoidal beams $(0 \cdot 3$ to $0.4 \mathrm{~m}$ thick), which provide the structural reticulate framing. Note that the area bounded by the resisting trapezoidal beams is a very thin $(6 \mathrm{~cm}) \mathrm{slab}$, which provides a small contribution to the overall inertia of the floor slabs.

Each floor was supported on two rows of four concrete columns having a rectangular cross-section of $1.50 \mathrm{~m}$ by $0.20 \mathrm{~m}$. Each one of the building columns rested on a single large-diameter pile with an enlarged base. Fig. 4 shows the eight piles supporting the tower. Each pile is defined by a 'coordinate' (R5, for instance) which refers to rows 3 or 5 in one direction and $\mathrm{Q}, \mathrm{R}, \mathrm{S}, \mathrm{T}$ in the perpendicular direction. Columns and piles Q3 and Q5 were common to towers 5 and 6 of Space building.

The large-diameter piles that were built are properly described as 'caisson piles'. They are built by a traditional handmade type of foundation, used in the Medellin region 


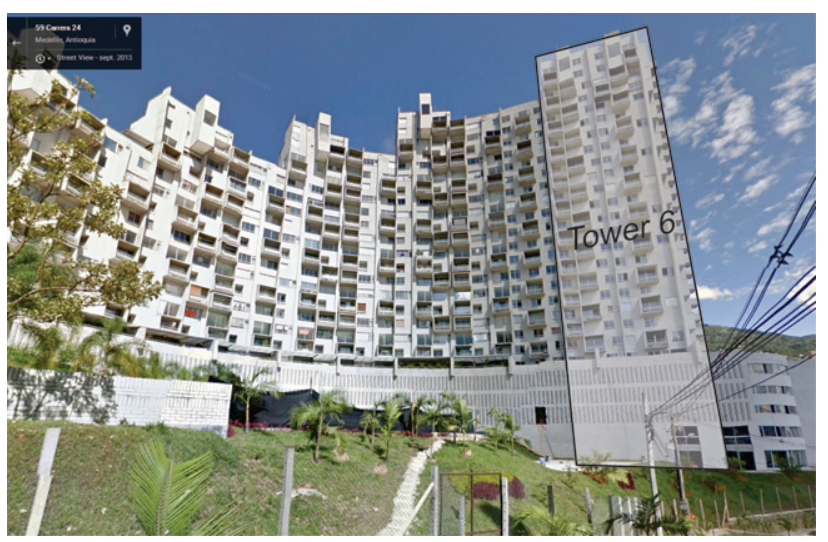

Fig. 1. Space building a few days before the collapse of the sixth tower (from Google Maps, Street View, September 2013)

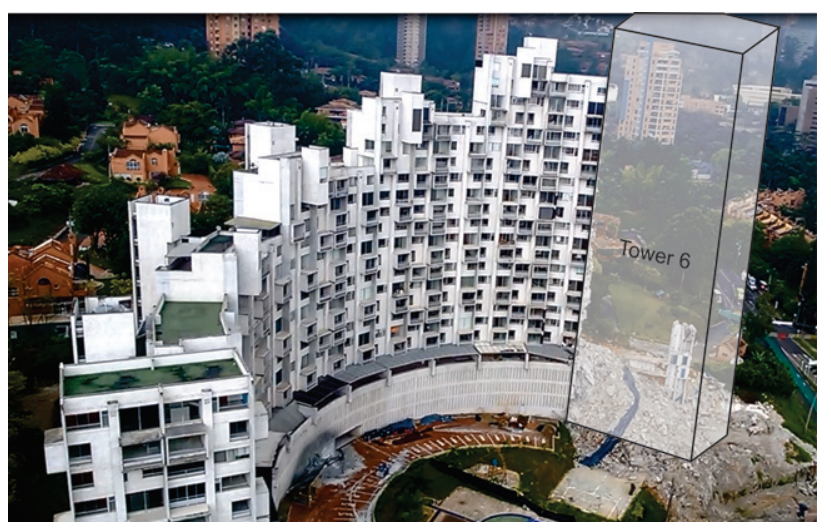

Fig. 2. Space building a few days after the collapse of Tower 6

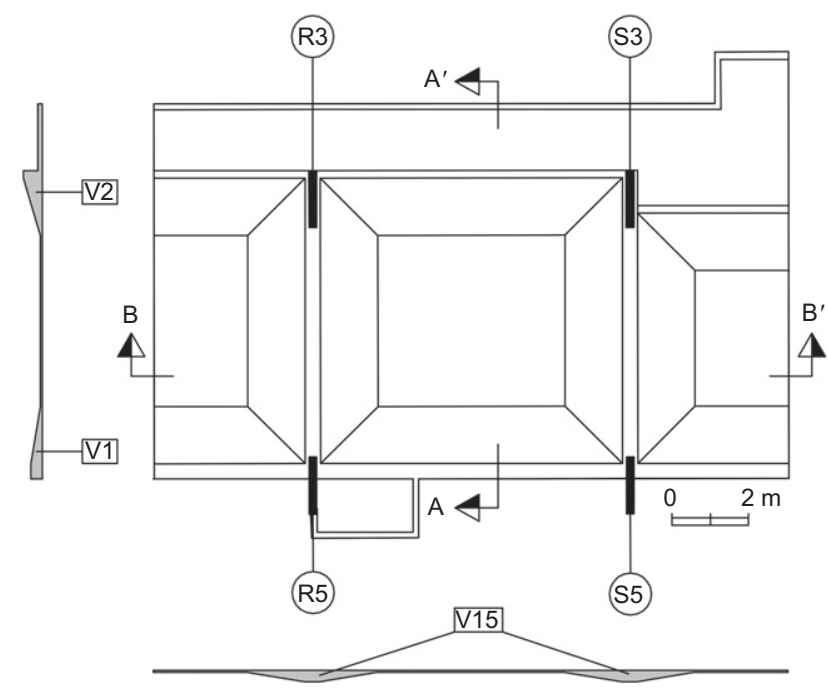

Fig. 3. Floor slab contributing to columns R3, R5, S3 and S5 of a typical floor of Tower 6. Plan view and two vertical cross-sections

where the soil has high variability, making it difficult for mechanised construction. Fig. 5 shows a schematic representation of the construction process of a caisson pillar foundation. The following steps describe the construction process.

(a) The construction begins with a handmade cylindrical excavation of the desired diameter, $1.2 \mathrm{~m}$ in the case of Space building, whose depth is usually $1 \mathrm{~m}$, see Fig. 5(a).

(b) The walls of the excavated cylindrical opening are protected by means of a truncated cone shield made of

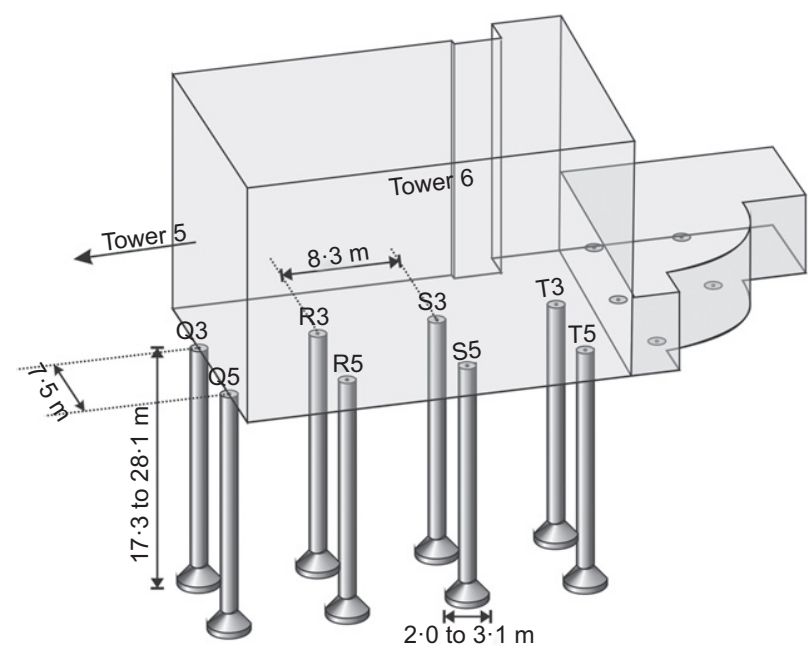

Fig. 4. Scheme of the original design of the pile foundation of Tower 6 of the Space building. Actual caisson lengths and base diameters depend on the soil encountered during construction; see Table 3 and Figs 19 and 20

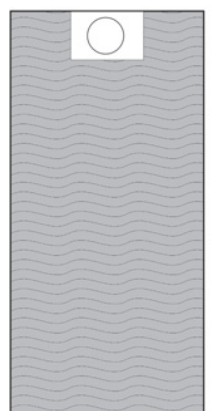

(a)

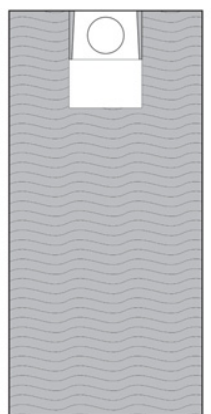

(b)

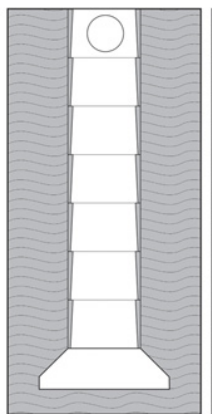

(c)

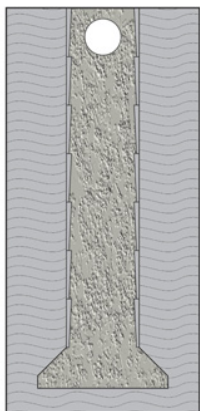

(d)
Fig. 5. Construction process of the foundation caissons: (a) manual excavation of the first section; (b) placing the concrete reinforcement of the first section and manual excavation of the second one; (c) manual excavation and reinforcement of the subsequent sections and excavation of the widened base; (d) concrete filling

concrete. The process continues with the next step of excavation, as shown in Fig. 5(b).

(c) The procedure is repeated until the desired depth, which is identified when the soil exhibits the necessary stiffness judged by the engineer in charge. Then a widened base is manually excavated, as shown in Fig. 5(c).

(d) Finally, the entire excavation is filled with concrete, as in Fig. 5(d). The upper $4 \mathrm{~m}$ of caissons are steel reinforced.

Although the construction process of handmade caissons offers the possibility of crossing difficult layers of soils, such as colluvium with rock blocks, the construction process becomes extremely difficult in the presence of water. However, excavating the enlarged base requires a soil with enough undrained strength to ensure stability of the opening.

The gravity loads in the original design were: $6 \mathrm{kN} / \mathrm{m}^{2}$ for the dead load, including the self-weight of the slab, the floor finishes and the walls, and $1.8 \mathrm{kN} / \mathrm{m}^{2}$ for the service live load. The bearing capacity of the piles was evaluated from an estimation of the friction angle, based on the results of the standard penetration tests, and using the bearing capacity factors recommendations of Berezantzev et al. (1961). The original project used safety factors of 1.5 for the shaft and 4 for the base, leading to a mean allowable shaft stress of $20 \cdot 3 \mathrm{kPa}$ and an allowable stress at the base of $1462 \mathrm{kPa}$. 


\section{RECORDED SETTLEMENTS DURING \\ CONSTRUCTION}

Settlements of the heads of piles of Tower 6 were measured by standard topographic procedures. Fig. 6 provides the evolution of the height of the building in terms of the level reached by every floor at the end of its construction. Also shown in the figure are the settlements measured on piles located along axes 3 and 5. Most of the caissons of the building settled no more than $30 \mathrm{~mm}$ at the end of construction with two exceptions. A pronounced settlement, reaching approximately $85 \mathrm{~mm}$, was measured on caisson R3 (Fig. 6(b)) and caisson S5 reached $50 \mathrm{~mm}$ (Fig. 6(c)).

Tall buildings, having a high aspect ratio, are expected to react as stiff structures against differential settlements. However, the outlined structure of Space building is relatively flexible due to the low inertia of the floor slabs. The large settlement recorded in pile R3 is a consequence of its faulty construction, described below, but it is also explained by the limited building stiffness against differential settlements. Fig. 7 shows the settlements profile along axes 3 and 5 of Tower 6 . It is conspicuous in Fig. 7(a) that a large relative differential settlement occurred between piles Q3 and R3 and between S3 and R3. The magnitudes of the differential settlements along axis 5 were significantly lower than along axis 3 .

Two 'crutched' piles, not shown in the figures, were built at opposite sides of pile R3 in an effort to brace it and reduce further settlements. The two supporting piles and pile R3

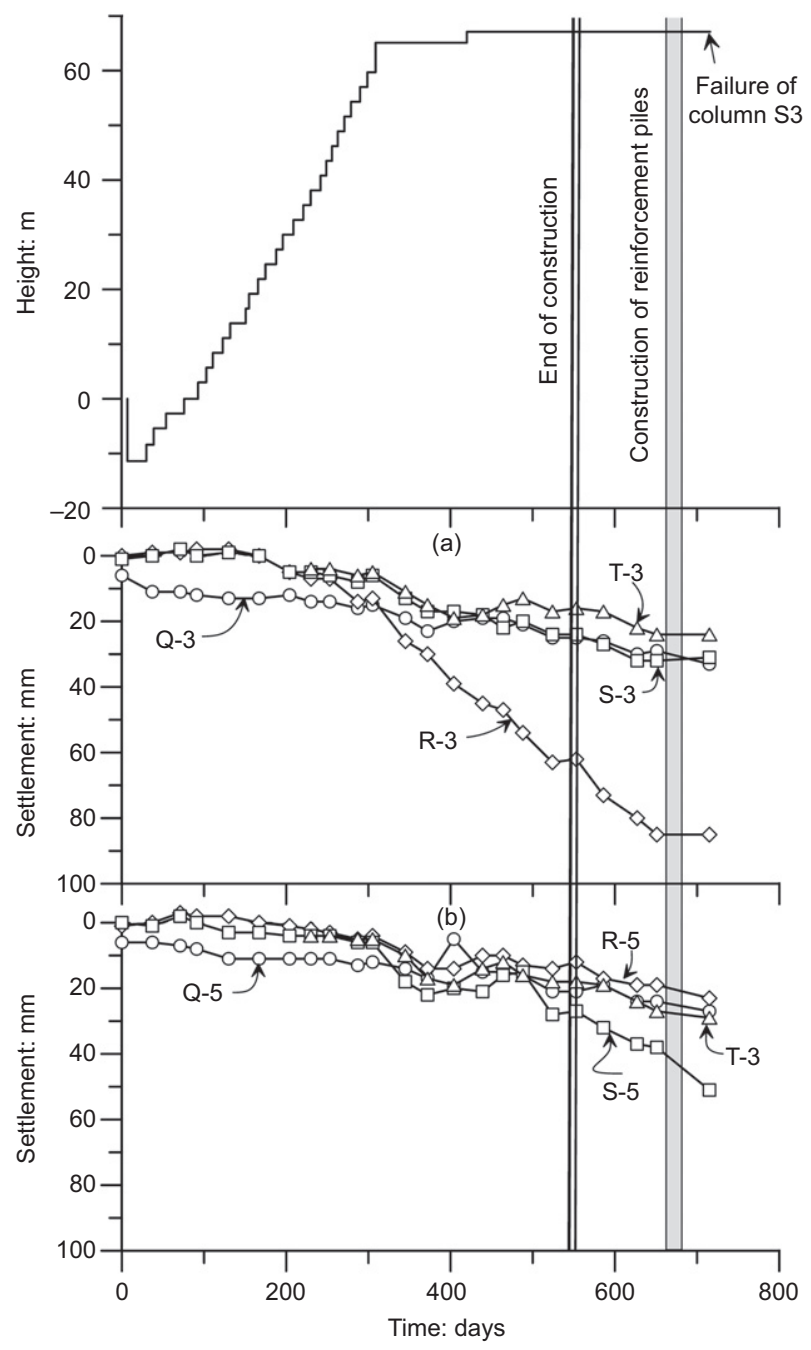

(c)

Fig. 6. (a) Progression of the height of the building (structure). (b), (c) Settlements along axes 3 and 5 were connected by a reinforced concrete beam. However, this strengthening action was adopted when the building had reached its maximum height (664-671 days after the initiation of construction). This reinforcement was effective in stopping the increase in settlement of pile R3 once the building was completed, but not before.

Consider in Fig. 8(a) the interaction between columns R3, $\mathrm{S} 3$ and S5. R3 and S5 experienced the largest recorded settlements at the end of construction ( 85 and $50 \mathrm{~mm}$, respectively), whereas $\mathrm{S} 3$ remained at a low value similar to the other columns of Tower 6. Therefore, column S3 is affected by the largest relative differential settlements in two perpendicular directions (1/157 in the R3-S3 direction and 1/380 in the S3-S5 direction) at the end of construction. The angular distortion evolved in time in the manner shown in Fig. 8(b).

In the case of R3-S3, the angular distortion remained negligible up to day 250 from the beginning of construction, when the tower reached a height of $40 \mathrm{~m}$. Beyond this time, the distortion increased rapidly, showing a linear trend with time, until the crutching piles supporting pile R3 became effective. This behaviour is an indication of the exhaustion of the bearing capacity of pile R3 when the height of the tower reached $40 \mathrm{~m}$. The $\mathrm{S} 3-\mathrm{S} 5$ angular distortion remained at a

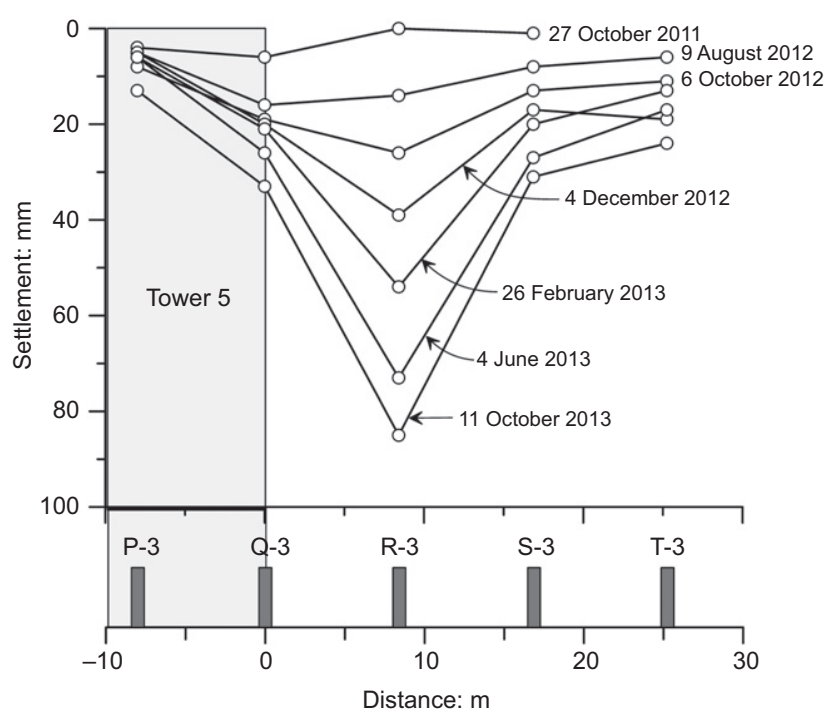

(a)

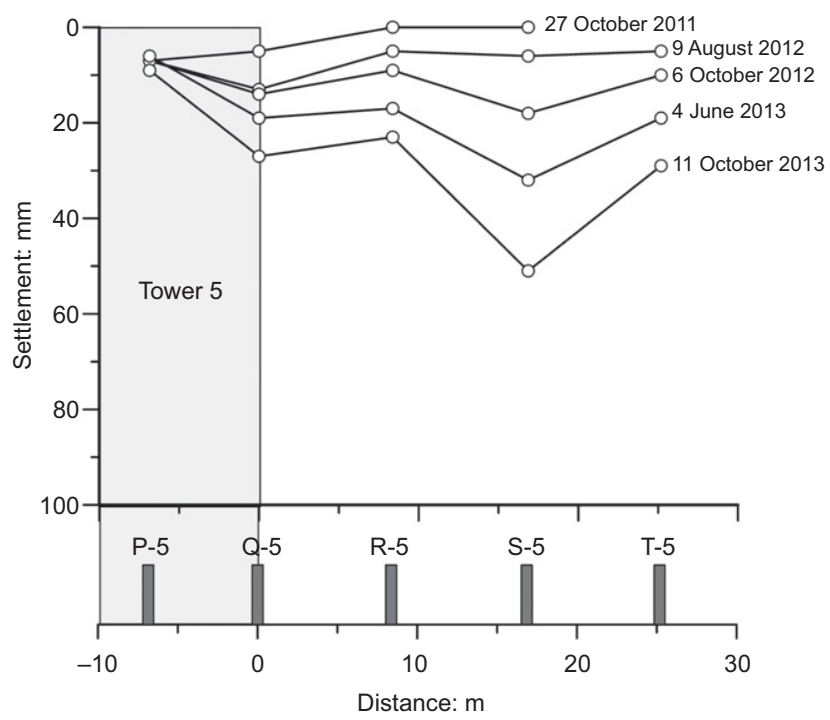

(b)

Fig. 7. Settlements along axes 3 and 5 


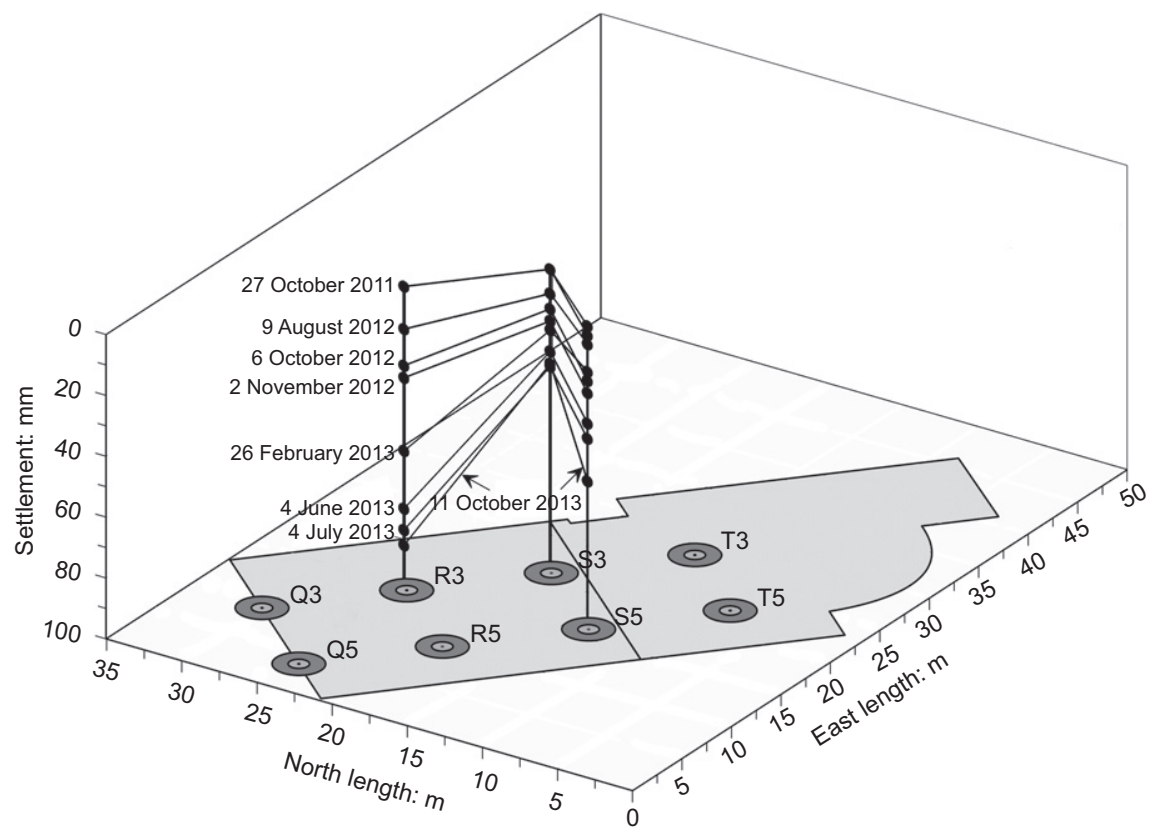

(a)

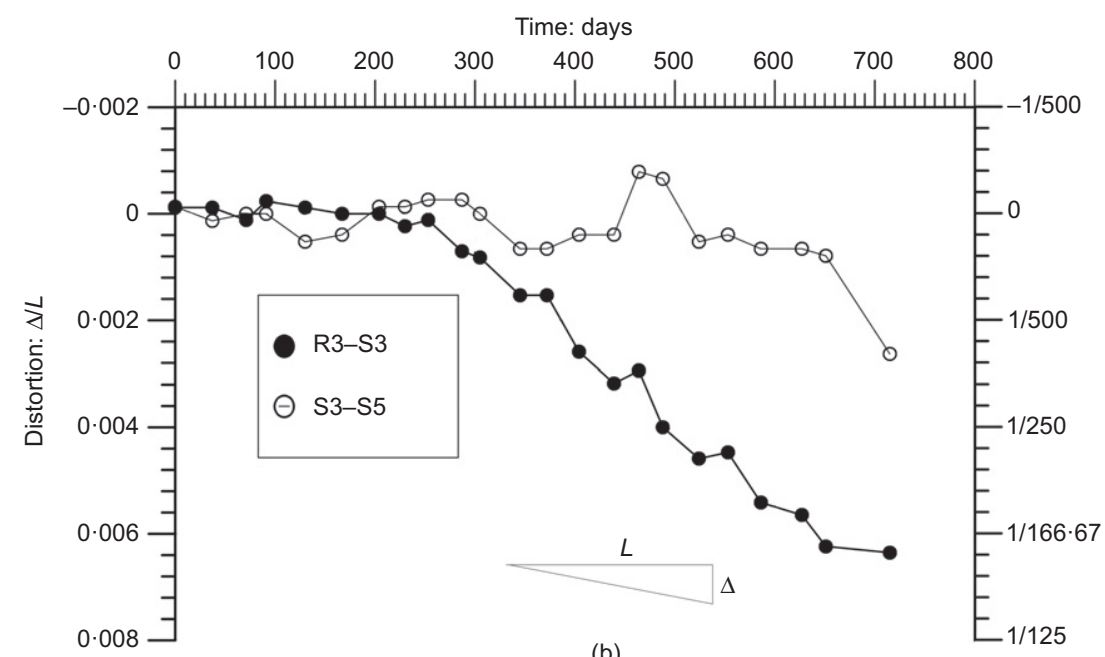

(b)

Fig. 8. Differential settlements between pile S3 and piles R3 and S5

very low value up to the end of the tower construction. It accelerated during the last 2 months before failure for reasons which remain unclear.

As a result, a significant load transfer occurred from piles R3 and S5 towards pile S3. This effect, quantified later, explains the observed structural failure in column S3 1 day before the collapse of Tower 6 (Fig. 9(a)). It is believed that the collapse of column S3 prompted the massive failure of the entire tower (Fig. 9(b)).

\section{GEOTECHNICAL CHARACTERISATION \\ OF THE SITE}

The forensic investigation of the foundation soil was divided into two parts. The first part includes the analysis of the previous soil investigation made for the project of the Space building (before construction). The second part, which includes basic characterisation, triaxial, ring shear and oedometric tests, was carried out after the collapse of Tower 6.

During the soil investigation for the entire building complex, ten boreholes were drilled, and several tests were performed on recovered soil samples. However, only one borehole (T05) lies in the zone occupied by Tower 6 . The distribution

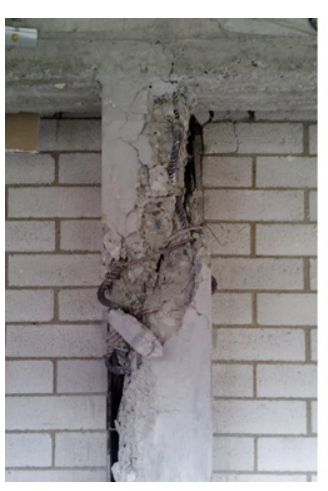

(a)

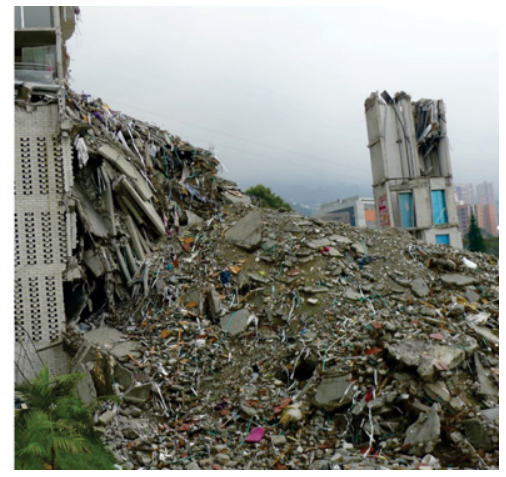

(b)

Fig. 9. (a) Column S3, 4th floor of Tower 6, on 11 October 2013 (building collapse: 12 October 2013 at 20.20 h). (b) Floor slabs piled up after collapse

with depth of $N_{\mathrm{SPT}}$ and water content at the site of the Space building complex is shown in Fig. 10. Large dispersions of values are observed, which, down to a depth of about $20 \mathrm{~m}$, essentially correspond to a layer of saprolite overlain by a $10 \mathrm{~m}$ 

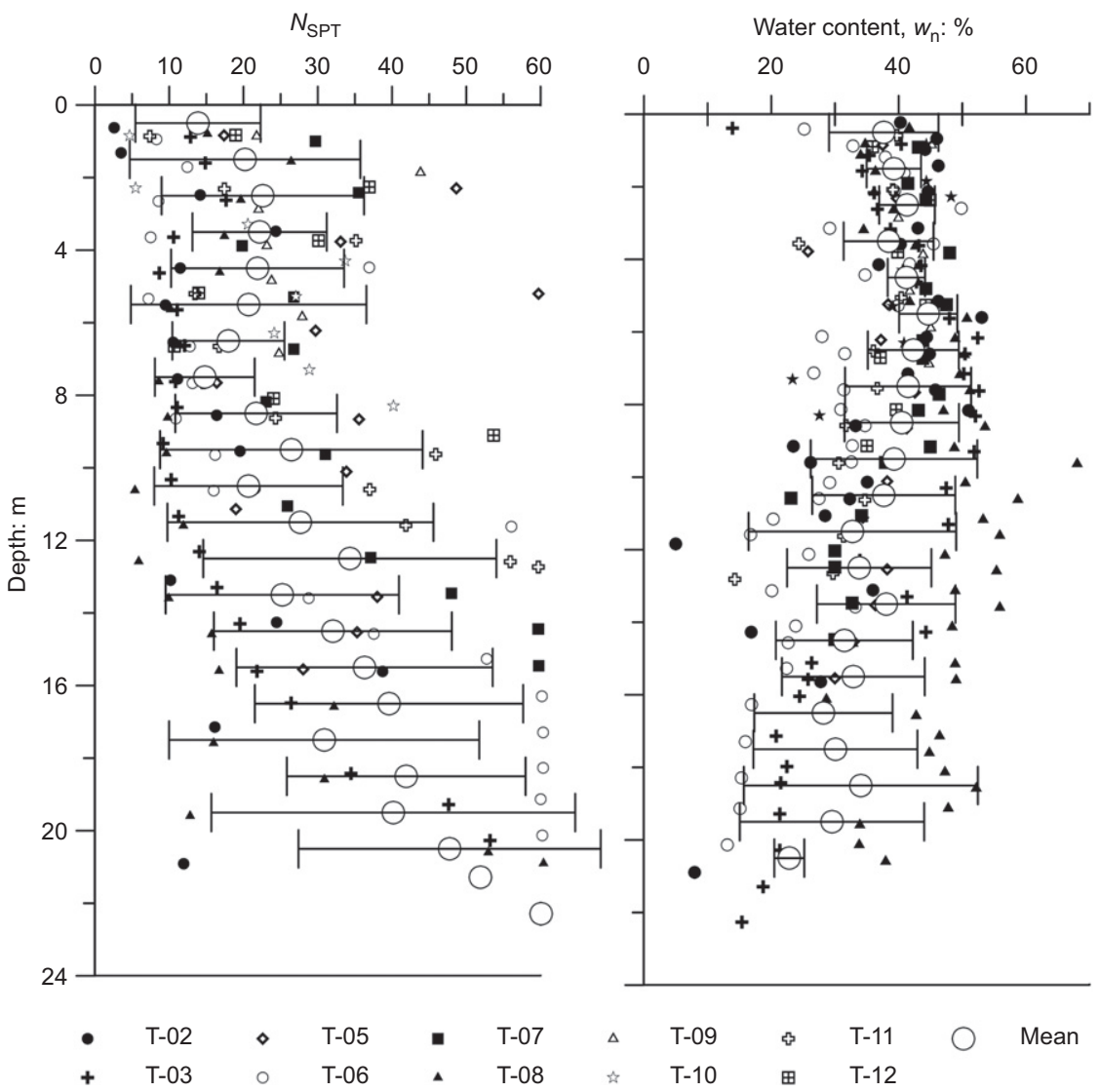

Fig. 10. Variation with depth of $N_{\mathrm{SPT}}$ and the natural water content at the site of the Space building complex for all boreholes carried out before construction

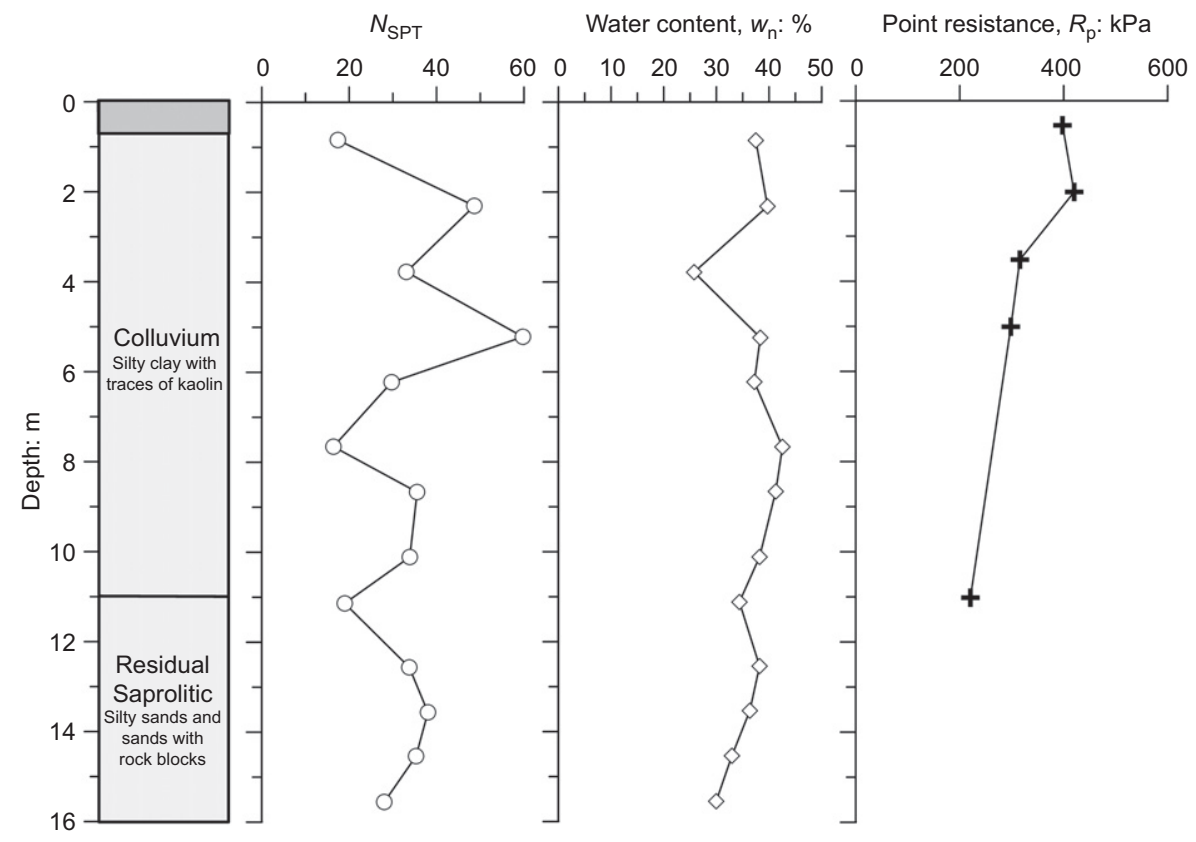

Fig. 11. Variation with depth along borehole T05 of $N_{\mathrm{SPT}}$, the natural water content and the penetration strength $\left(R_{\mathrm{p}}\right)$ determined with a hand penetrometer on recovered cores

thick layer of colluvium. In the saprolitic level, the average standard penetration test (SPT) blow count, $N_{\text {ave }}$, increases with depth from $N_{\text {ave }}=20-22$, at a depth of $10 \mathrm{~m}$, to $N_{\text {ave }}=50$, at depths of 20-22 m. However, the risk of finding levels of soft to medium strength remains high in the entire building area.

The average water content, $w_{\text {ave }}$, decreases also with depth, from $w_{\text {ave }}=40 \%$ at the surface to $w_{\text {ave }}=30 \%$ at depth. The observed heterogeneity, considering all data points, is consistent with SPT variability. However, the two layers mentioned (colluvium and saprolite) could hardly be distinguished when looking at the boreholes logs.

Figure 11 provides the SPT count number, the natural water content, $w_{\mathrm{n}}$, and the strength measured with a hand penetrometer, $R_{\mathrm{p}}$, in borehole T05, performed in the area occupied by 
Tower 6 . The soil along borehole T05 is a colluvium with some traces of kaolinite down to $11 \mathrm{~m}$, followed by a residual saprolitic soil consisting of silty sands with rock blocks.

After the building had collapsed, two boreholes were carried out to characterise the soil near piles S3 and S5. Also, one exploratory, large-diameter, handmade well $(1.2 \mathrm{~m}$ dia. and $18 \mathrm{~m}$ long) was excavated adjacent to the R3 caisson with the purpose of identifying the state of the widened base of the pile, as well as to recover large undisturbed samples for laboratory testing. Fig. 12 shows the location of the boreholes and the exploratory well.

Figure 13 shows the distribution of the basic identification parameters determined in the tests. The fines content in all samples exceed $70 \%$ and the soils are high-plasticity silts $(\mathrm{MH})$ in the upper $10 \mathrm{~m}$, followed by medium-plasticity silts (ML) at greater depths. The liquid limit was in the entire profile larger than $40 \%$ and values of $70-80 \%$ were measured at depths of 3 to $7 \mathrm{~m}$. Unit weight $\left(\gamma_{\text {sat }}\right)$ is correlated with plasticity: values of the order of $\gamma_{\text {sat }}=16 \mathrm{kN} / \mathrm{m}^{3}$ are found in

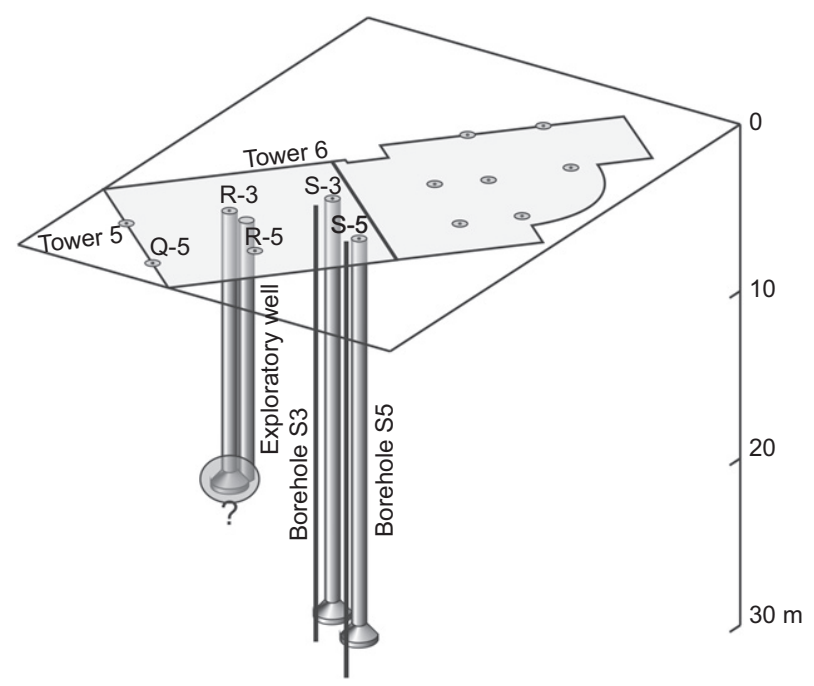

Fig. 12. Location of the large-diameter exploratory well and boreholes S3 and S5 drilled after the collapse of Tower 6 highly plastic samples, and values around $\gamma_{\text {sat }}=18 \mathrm{kN} / \mathrm{m}^{3}$ correspond to medium plasticity. Void ratios calculated with the assumption of sample saturation and $\gamma_{\text {solids }}=27 \mathrm{kN} / \mathrm{m}^{3}$ range between 1.8 (high plasticity) and 1.1 (medium plasticity). The mineralogy of two samples tested reflect the soil heterogeneity. One was a mixture of kaolinite, mica and vermiculite (a brown, laminar mica). The second one was dominated by feldspar and had a long list of minerals present: kaolinite, chlorite, amphibolite, quartz, goethite and halloysite.

Undrained triaxial and oedometric tests were carried out on the undisturbed block samples taken from the exploratory well. Fig. 14 shows the results of oedometric tests at depths with the interval 6-17 m. Compression indices measured in the normally consolidated state range between 0.35 and 0.58 . Fig. 15(a) shows the result of consolidated undrained triaxial tests carried out on a sample taken at a depth of $16.5 \mathrm{~m}$. The tested soil shows a moderately contractant behaviour.

Table 1 summarises the main strength and compressibility parameters derived from these tests. The critical state friction angle remained reasonably constant with depth $\left(30-34^{\circ}\right)$. Compressibility on loading and unloading was more heterogeneous.

Records of pile settlement, analysed before, indicated an excessive settlement of pillar R3. The purpose of the exploratory well was not only to take undisturbed samples, but also to investigate, by visual inspection, the existence and state of the widened base of the pillar R3.

The construction of the exploratory well followed the same construction process employed in the excavation of the piles. This well experienced the same difficulties suffered during pile construction: high water flows below the water table, found at $5 \mathrm{~m}$ depth, and soil disaggregation and instability of the walls of the borehole at its final depth. Furthermore, the well found no evidence of any base enlargement of pile R3.

Figure 16 describes the problems of the construction of the pillar R3 and the difficulties encountered during the excavation of the inspection well. The construction process followed in pile R3 is described as follows.

(a) When excavating below the groundwater level, water flowed into the excavation. This situation led to

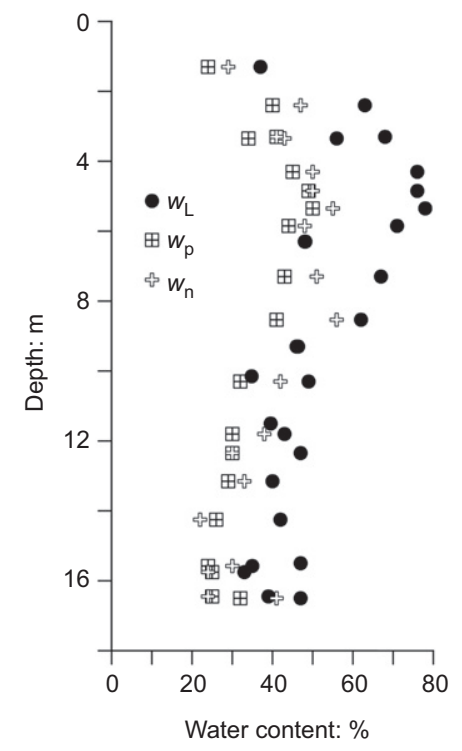

(a)

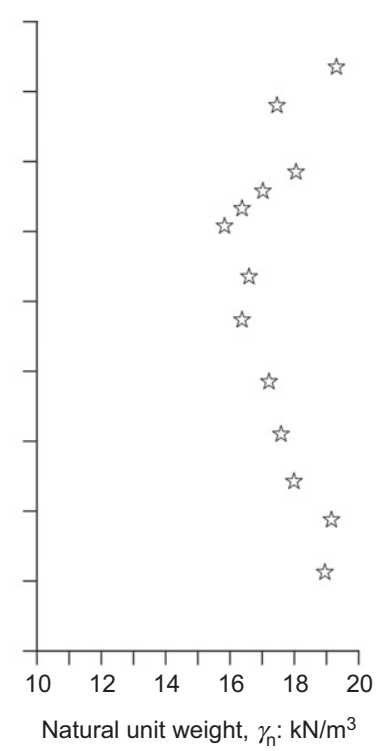

(b)

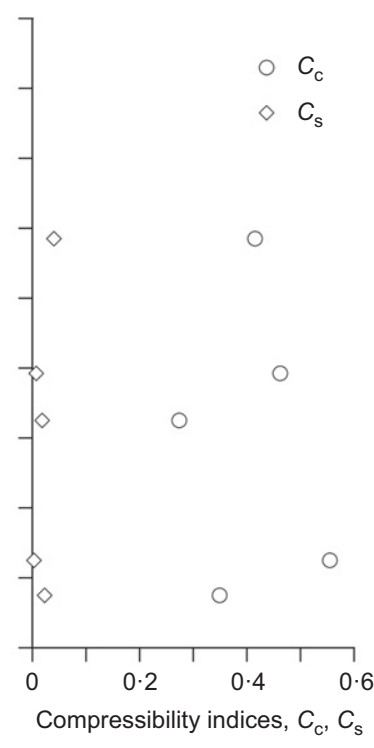

(c)

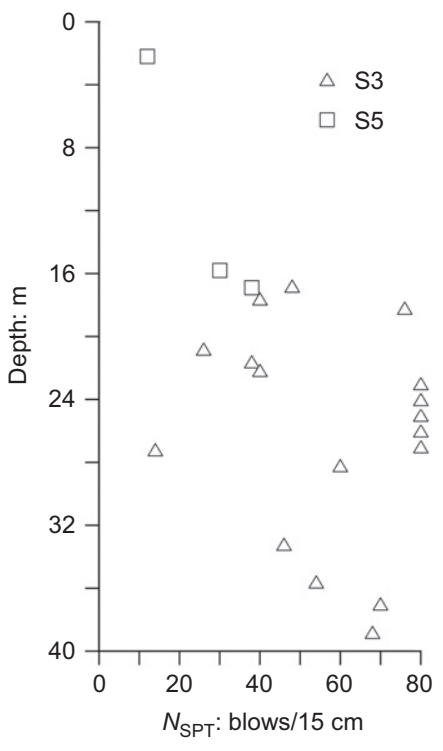

(d)

Fig. 13. Distribution with depth in boreholes S3 and S5 of: (a) Atterberg limits and water content; (b) unit weight; (c) compressibility indices; (d) SPT blow count 


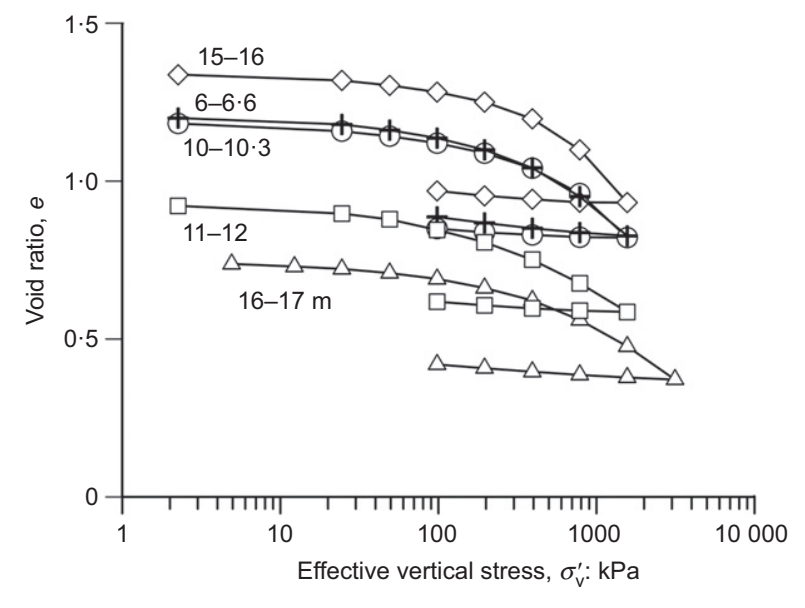

Fig. 14. Oedometric tests on undisturbed samples taken at four depth intervals in the exploratory well

instability of the walls and bottom of the excavation; see Fig. 16(a).

(b) Problems increased near the base because the water pressure increased and the construction of the flared base became extremely difficult. Water pressure led to instability and collapse of the soil around the widened base; see Fig. 16(b). The excavation was abandoned in a hurry and, presumably, softened soil invaded the bottom of the excavation.

(c) Finally, the entire excavation was filled with concrete. The soil around the base was highly disturbed because the soil collapsed into the excavation, as shown in Fig. 16(c).

The next sections describes the model adopted for the foundation soil and the selection of parameters.

\section{MODELLING FOUNDATION SOIL}

Given the variability of Tower 6 foundation soils, no layers were introduced in the analysis. In fact, the heterogeneity observed in previous plots (Fig. 10) made it impractical to introduce internal boundaries separating soil layers. The adopted soil properties have the character of average values.

The 'hardening soil' constitutive model, described in Brinkgreve et al. (2016), defines the undisturbed soil around the foundation caissons. The model considers two hardening mechanisms: a shear hardening and a volumetric hardening defined by an elliptical cap. Other features of the model are a stress-dependent isotropic elastic stiffness following a power law, a Mohr-Coulomb failure envelope and a tension cut-off (assumed nil).

Three sets of parameters, collected in Table 2, define the soil model.

(a) Elasto-plastic parameters. In the elastic domain, a hyperbolic law is defined by two stiffness parameters, a Poisson ratio and a power parameter, $m$, which introduces the dependence of moduli with mean stress. The stiffness parameters are expressed in terms of the compressibility indices $C_{\mathrm{c}}, C_{\mathrm{s}}$ and the initial void ratio, $e_{0}$.

(b) Effective friction angle, $\phi^{\prime}$, effective cohesion, $c^{\prime}$, and the dilatancy angle $\psi$ ( $\psi=0$ in all cases).

(c) Parameters associated with the cap yield surface. Main parameters are the shape parameter, $M$, and the isotropic mean preconsolidation stress, $p_{\mathrm{p}}$, which is a state variable controlled by hardening rules.
Details of the model are found in the original reference (Schanz et al., 1999). Default values suggested in this reference for other model parameters were adopted.

The selection of constitutive parameters was guided by laboratory tests performed and by the field performance (recorded settlement over time under the building load) of two caissons, R3 and S3, which experienced maximum and minimum settlements.

The four undrained triaxial tests carried out on undisturbed samples recovered in the exploratory well adjacent to caisson R3 at a depth of $16.5 \mathrm{~m}$ provided a benchmark to find a first estimation of the parameters of the soil model. Tests results are given in Fig. 15(a).

The position of the cap yield surface requires information on (maximum) past isotropic yield stress. This can be achieved if the OCR and the $K_{0}$ values could be estimated. A special feature of residual soils in some areas is a $K_{0}$ ratio greater than one. This characteristic was identified in the experimental fields of the University of Brasilia (Mendoza, 2013) and the Federal University of Paraná (Cavalcante et al., 2007). This feature is related to a strong lixiviation process (chemical weathering), the geology (removal of layers) and the influence of the topography (or geomorphology) of the different sites (Cavalcante et al., 2007). Fig. 17 shows the results of the soil profile from a Marchetti dilatometer test in the new experimental field of the University of Brasilia. This figure provides evidence of high values of the $K_{0}$ ratio and high overconsolidation ratio (OCR) in residual soils. However, there is no information on the in situ state of stress and the OCR of the saprolitic soil. An additional insight on the effect of OCR and $K_{0}$ could be gained by checking the effect of alternate pairs of $\left(K_{0}\right.$, OCR $)$ on the calculated response of the triaxial tests performed. This is shown below.

For a given $\left(K_{0}\right.$, OCR $)$ pair, the steps applied in the simulation of these tests are as follows.

(a) Generate the overconsolidation mean effective stress by applying an isotropic value $p_{0}^{\prime}$. This value is obtained by accepting that the initial state of stress at a depth of $16.5 \mathrm{~m}$ belongs to the yield surface.

(b) Apply the initial isotropic stress state to the four samples tested ( $p^{\prime}=100,200,300$ and $\left.400 \mathrm{kPa}\right)$.

(c) Perform the test by increasing the vertical stress in steps (at constant total horizontal stress).

Figure 15(b) shows the model response for the particular case $\mathrm{OCR}=3 ; K_{0}=1 \cdot 3$. The agreement is reasonably good except for the low confining stress of $100 \mathrm{kPa}$. Calculated pore water pressures developed also match the test measurements reasonably well.

It was realised that alternative values of the $\left(K_{0}\right.$, OCR) pair, plotted in Fig. 18, led to a similar acceptable match of the triaxial tests. Moreover, changing the adopted $\left(K_{0}, \mathrm{OCR}\right)$ values, following Fig. 18, had a negligible effect on the pile foundation response.

The adopted compression index, $C_{\mathrm{c}}=0 \cdot 25$, which enters the simulation of the triaxial test and contributes to a good match of settlements observed in piles R3 and S3, is lower than the $C_{\mathrm{c}}$ values obtained at high vertical stress $(900-1500 \mathrm{kPa})$ in the oedometer tests performed (Figs 13 and 14). However, it fits better the oedometric compression curves for the intermediate stress range, which is better adapted to the triaxial tests described and 'in situ' conditions around the piles.

Table 2 also includes the constitutive parameters assigned to the re-worked and softened material located below the tip of pile R3 ('soft soil'). As described, during the construction of pile R3 the water flow entering the excavation 

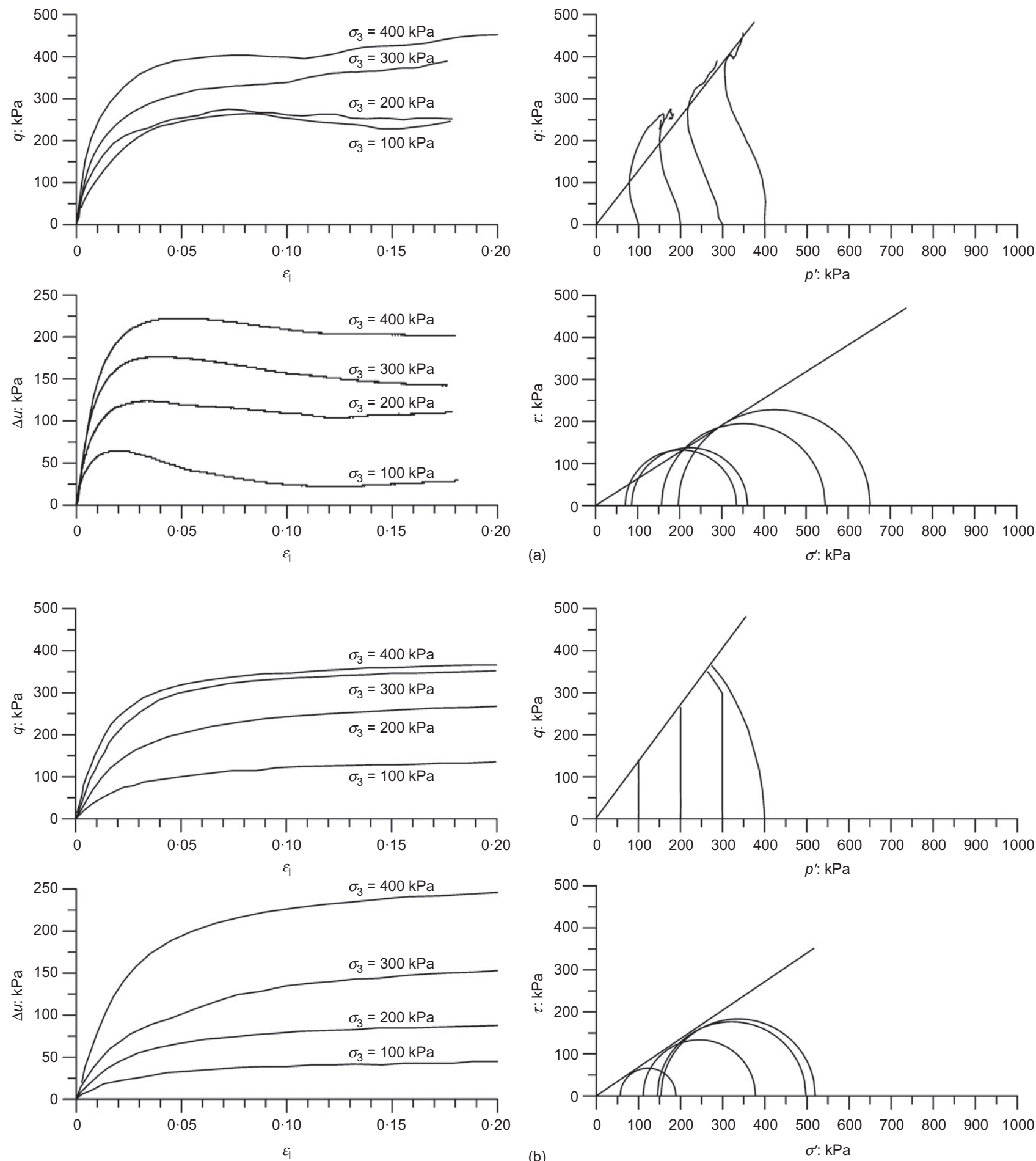

Fig. 15. Consolidated undrained triaxial tests on samples from the exploratory caisson at a depth close to $16 \cdot 5 \mathrm{~m}$ : (a) test results; (b) hardening soil model predictions. $\sigma_{3}$, confining stress; $\varepsilon_{1}$, axial strain; $q$, deviator stress; $p^{\prime}$, effective mean stress; $\Delta u$, increase in pore pressure; $\tau$, shear stress

disaggregated the soil, placing it in a loose condition. Certainly this reworked soil was very compressible. For this reason, based on judgement, the value of $C_{\mathrm{c}}$ was increased to $C_{\mathrm{c}}=2 \cdot 5$ (ten times if compared with the undisturbed soil), the initial void ratio was increased to 1.5 and the effective friction angle was reduced to $20^{\circ}$.

\section{MODELLING TOWER 6 AND ITS FOUNDATION \\ Geometry and materials}

A finite-element model was elaborated to study the causes of the collapse of the Tower 6 of the Space building.
Table 1. Summary of results of oedometric and triaxial consolidated undrained tests on samples from the exploratory well

\begin{tabular}{l|c|c|c}
\hline $\begin{array}{l}\text { Depth } \\
\text { range: } \mathrm{m}\end{array}$ & $\begin{array}{c}\text { Critical state friction } \\
\text { angle: degrees }\end{array}$ & $\begin{array}{c}\text { Compressibility } \\
\text { index, } C_{\mathrm{c}}\end{array}$ & $\begin{array}{c}\text { Swelling } \\
\text { index, } C_{\mathrm{s}}\end{array}$ \\
\hline $3 \cdot 0-3 \cdot 6$ & 32 & - & - \\
$6 \cdot 0-6 \cdot 6$ & 30 & $0 \cdot 415$ & $0 \cdot 04$ \\
$10 \cdot 0-10 \cdot 3$ & - & $0 \cdot 462$ & $0 \cdot 007$ \\
$11 \cdot 0-12 \cdot 0$ & - & $0 \cdot 274$ & $0 \cdot 018$ \\
$15 \cdot 0-16 \cdot 0$ & 34 & $0 \cdot 555$ & $0 \cdot 003$ \\
$16 \cdot 0-17 \cdot 0$ & 32 & $0 \cdot 349$ & $0 \cdot 023$ \\
\hline
\end{tabular}




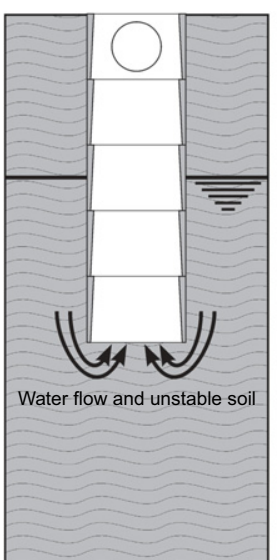

(a)

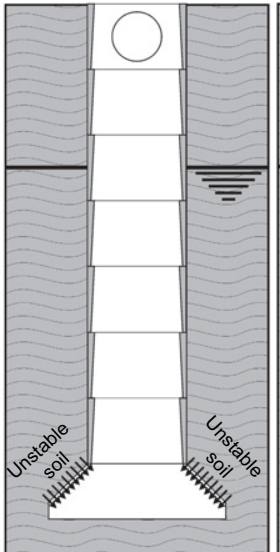

(b)

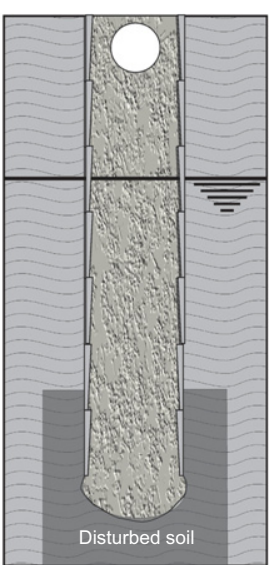

(c)
Fig. 16. Schematic representation of the difficulties encountered during construction of the foundation piles: (a) flow of water and soil into the excavation; (b) falling of the soil above the widened base; (c) pile without the widened base with disturbed soil around the base
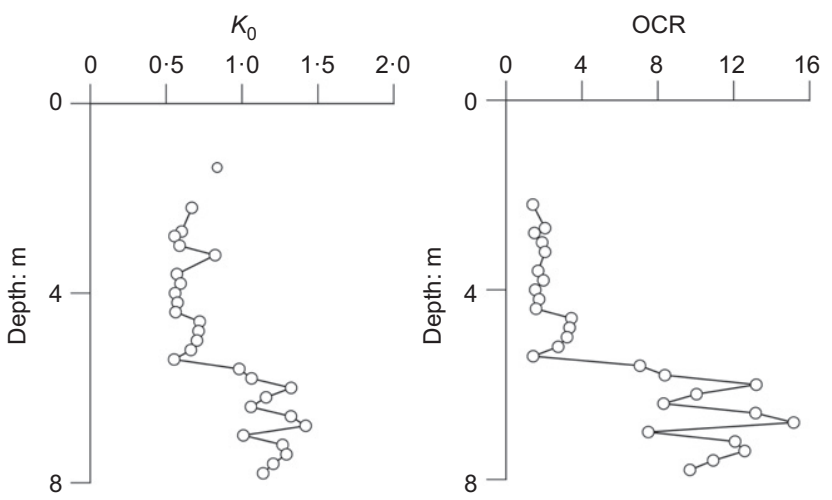

Fig. 17. $K_{0}$ and OCR profiles measured by Mendoza (2013) in a residual soil of Brasilia

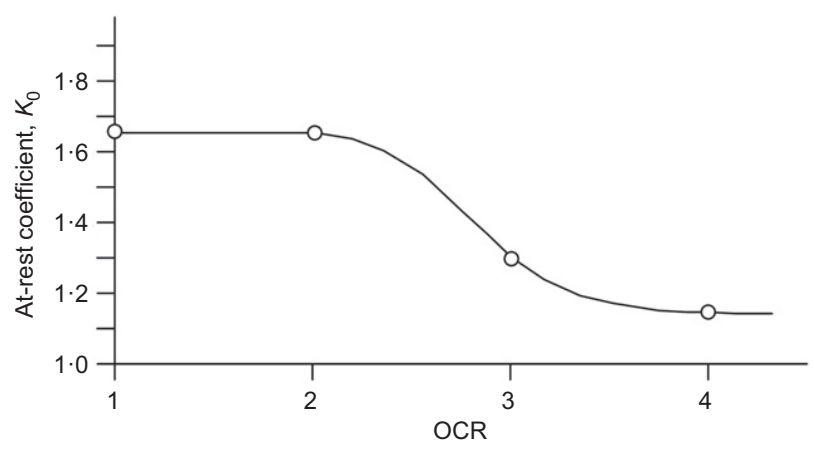

Fig. 18. $\left(K_{0}\right.$, OCR) combinations which lead to an acceptable reproduction of triaxial tests and an essentially similar response of the pile foundation

The Plaxis 3D finite-element software (Brinkgreve et al., 2016) was used to perform a three-dimensional (3D) analysis; it uses a finite-element mesh made of soil elements (soil and piles), interface elements (contact piles-soil) and beam elements (columns and beams of the 24-storey building).

Figure 19 shows the finite-element model, which has 48432 ten-noded soil elements with an average element size of $2.644 \mathrm{~m}$. The soil region is a right rectangular prism of dimensions $64.90 \mathrm{~m} \times 47.50 \mathrm{~m}$ and a height of $45.00 \mathrm{~m}$; it encloses the eight caissons of Tower 6. The distance between the piles and the nearest boundary is $20.00 \mathrm{~m}$ in the horizontal direction and $16.90 \mathrm{~m}$ from the bottom of the
Table 2. Parameters adopted in hardening soil model $\left(\gamma=17 \mathrm{kN} / \mathrm{m}^{3} ; \psi=0^{\circ} ; K_{0}{ }^{\mathrm{NC}}=0 \cdot 426\right)$

\begin{tabular}{l|l|l|l}
\hline Symbol & Reference soil & Soft soil & Units \\
\hline$e_{0}$ & 1 & $1 \cdot 5$ & - \\
$C_{\mathrm{c}}$ & $0 \cdot 25$ & $2 \cdot 5$ & - \\
$C_{\mathrm{s}}$ & $0 \cdot 01$ & $0 \cdot 1$ & - \\
$m$ & 1 & 1 & - \\
$c^{\prime}$ & 0 & 0 & $\mathrm{kPa}$ \\
$\phi^{\prime}$ & 35 & 20 & degrees \\
$v_{\mathrm{ur}}$ & $0 \cdot 20$ & $0 \cdot 2$ & - \\
$K_{0}$ & $1 \cdot 30$ & $0 \cdot 7$ & - \\
$\mathrm{OCR}$ & 3 & 1 & - \\
$k$ & $10^{-8}$ & $2 \times 10^{-8}$ & $\mathrm{~cm} / \mathrm{s}$ \\
\hline
\end{tabular}

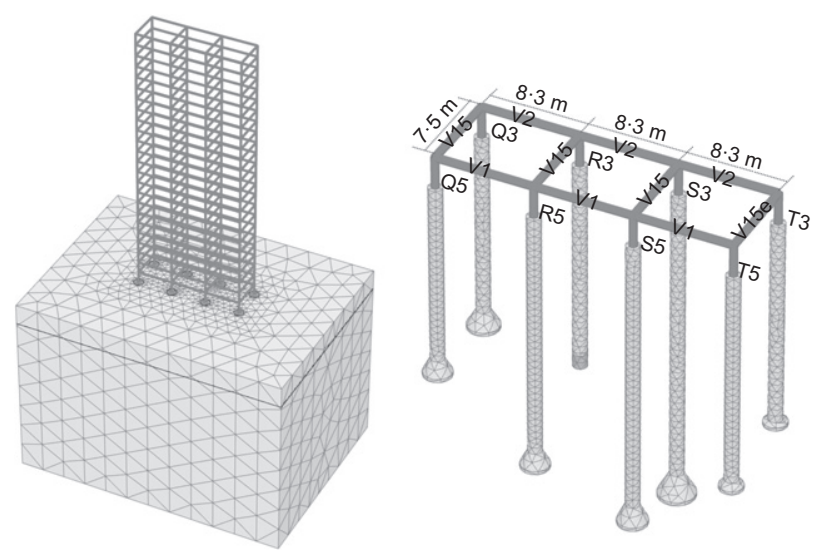

Fig. 19. Finite-element model of Tower 6 of the Space building

longest pile to the base of the model. These dimensions reduce the effect of the boundaries on the caisson's behaviour.

Three coaxially stacked geometrical objects represent piles: $(a)$ a cylinder for the shaft; $(b)$ a truncated cone for the widened footing; and (c) a cylinder for the base of the widened footing. As shown in Table 3, the geometry of a generic pile is defined by five parameters. Note that pile R3 does not have a widened base; furthermore, around the base of this pile the soil was softened trying to reproduce the failure of the bottom part of the caisson excavation during the construction phase. Difficulties encountered when excavating pile R3 were immediately identified. However, the excavation was concreted in the usual way and no remedial measures were adopted during the subsequent construction of the building. Two 'crutched' piles were built and connected to the R3 pile when the building was already completed (see Fig. 6).

Regarding the building structure, each typical floor has ten beams and eight columns modelled using elastic beam elements that sustain axial, shear forces and bending moments. The beam-column framework is connected to the eight foundation piles (Fig. 19).

The beam and column structural model adopted did not consider any extra stiffness attributed to masonry partitions and walls. Visual observations of Tower 6 apartments, before failure, as well as the examination of the remaining towers of the Space complex revealed a frequent fissuring of masonry. It was also a common construction practice to place some isolation material between the main masonry walls and the structural columns. However, distinct fissuring was also observed in structural slabs. In view of these observations, it was decided not to increase the nominal stiffness of the reinforced concrete structure by any contribution of masonry walls. 
Table 3. Geometric parameters of piles (in m)

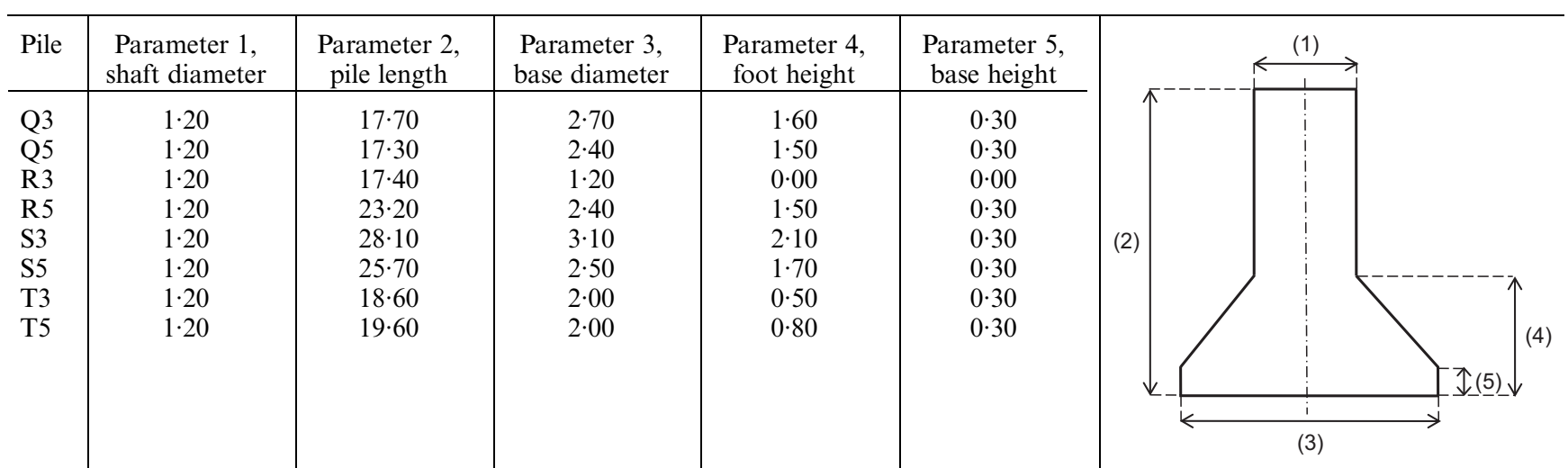

Note: pile dimensions came from the original design, except for pile R3 for which the forensic study confirms the absence of an enlarged base.

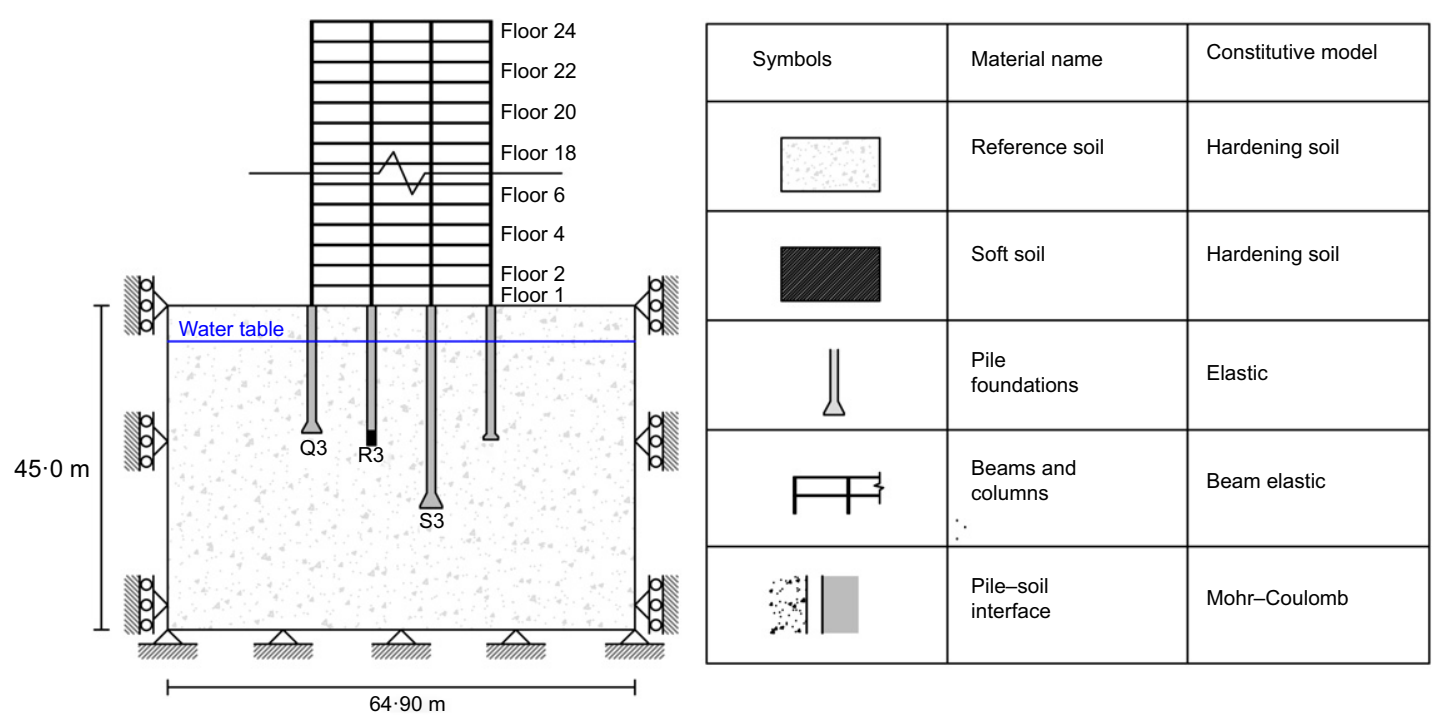

Fig. 20. Cross-section along axis 3, boundary conditions of finite-element analyses and constitutive models for materials involved

Table 4. Properties of the beam element types

\begin{tabular}{l|l|l|l|l|l|c}
\hline \multirow{2}{*}{ Symbol } & \multicolumn{5}{l}{ Beam element (see Figs 3 and 19) } & \multirow{2}{*}{ Units } \\
\cline { 2 - 7 } & V1 & V2 & V15 & V15e & Columns \\
\hline$A$ & $5 \cdot 05 \times 10^{-1}$ & $5 \cdot 20 \times 10^{-1}$ & $6 \cdot 60 \times 10^{-1}$ & $3 \cdot 90 \times 10^{-1}$ & $3 \cdot 00 \times 10^{-1}$ & $\mathrm{~m}$ \\
$\gamma$ & $49 \cdot 69$ & $49 \cdot 69$ & $49 \cdot 69$ & $49 \cdot 69$ & $0 \cdot 00$ & $\mathrm{kN} / \mathrm{m}^{3}$ \\
$E$ & $30 \times 10^{6}$ & $30 \times 10^{6}$ & $30 \times 10^{6}$ & $30 \times 10^{6}$ & $30 \times 10^{6}$ & $\mathrm{kN} / \mathrm{m}^{2}$ \\
$I_{3}$ & $5 \cdot 61 \times 10^{-3}$ & $8 \cdot 40 \times 10^{-3}$ & $3 \cdot 77 \times 10^{-3}$ & $2 \cdot 41 \times 10^{-3}$ & $5 \cdot 63 \times 10^{-2}$ & $1 \cdot 00 \times 10^{-3}$ \\
$I_{2}$ & $1 \cdot 19 \times 10^{-1}$ & $9 \cdot 74 \times 10^{-2}$ & $4 \cdot 19 \times 10^{-1}$ & $9 \cdot 57 \times 10^{-2}$ & $\mathrm{~m}^{4}$ \\
\hline
\end{tabular}

Linear elastic models described the caissons and building beams. A hardening soil model described the behaviour of the soils involved and an interface model was adopted for the soil-pile contact. Figure 20 summarises the set of constitutive models adopted.

Piles were described by standard concrete parameters $\left(E=25 \times 10^{6} \mathrm{kN} / \mathrm{m}^{2} ; v=0.3\right.$ and $\left.\gamma=24 \mathrm{kN} / \mathrm{m}^{3}\right)$.

The material model for the building structure is based on Mindlin's theory for elastic beams that allows beam deflections due to bending moments and shear stresses, as well as changes in length. Mindlin's theory relates the force components (axial force, shear force and bending moments) with the strain/gradient and curvature components of the beam. These relationships depend on the Young's and shear moduli, $E, G$ (taken as $E / 2$ ), the cross-sectional area, $A$, and the moment of inertia about the two local axes of the beam, $I_{2}, I_{3}$.

The weight of each floor of the building was applied to each beam element (except the columns) by increasing its unit weight, $\gamma$. This procedure was simply a matter of convenience of calculations. The weight of the structure, masonry elements and surcharges was calculated and it was then attributed to the beam unit weights. Table 4 summarises the characteristics of the beam elements of the model.

Pile-soil contact was simulated by interface elements. Two situations were considered: a non-degraded interface or a 
Table 5. Parameters used in the Mohr-Coulomb model for degraded pile-soil interfaces

\begin{tabular}{l|l|l}
\hline Symbol & Interface soil & Units \\
\hline$E$ & 2300 & $\mathrm{kN} / \mathrm{m}^{2}$ \\
$v$ & $0 \cdot 30$ & - \\
$c$ & $0 \cdot 00$ & $\mathrm{kN} / \mathrm{m}^{2}$ \\
$\phi^{\prime}$ & $15 \cdot 50$ & degrees \\
$\psi$ & 0 & degrees \\
\hline
\end{tabular}

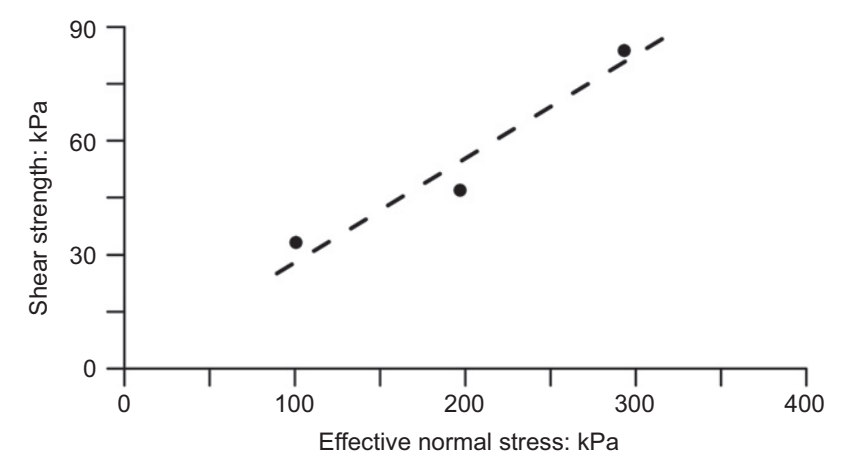

Fig. 21. Residual friction envelope measured in a ring shear test

degraded interface; the latter was assumed to be under residual conditions. Interfaces, in the finite-element program used, are linked to a constitutive model for the continuum. The non-degraded interface is associated with the reference soil described previously. The interface for residual conditions was associated with an elastoplastic Mohr-Coulomb model. Table 5 indicates the parameters for the degraded interface. The relevant parameter is the residual friction angle $\left(15 \cdot 5^{\circ}\right)$, which was estimated by a ring shear test on the high-plasticity saprolitic soil (Fig. 21). The outer surfaces of the vertical pile shafts and the conical lateral surfaces of the enlarged bases are degradable interfaces because they will evolve from an initial non-degraded state to a residual state as relative displacements accumulate. The horizontal pile-soil contact at the pile tip was assumed to be non-degradable. The transition from a non-degraded to a residual degraded state is described in the next section.

A stress ratio $K_{0}=1 \cdot 3$ and $\mathrm{OCR}=3$ define the initial and yielding stress state. Results are moderately sensitive to these values, which were approximated to fit better the observed settlements of piles R3 and S5. See, however, Fig. 18 and the associated discussion. The water level in the model was located $5 \mathrm{~m}$ below the horizontal upper surface, following field observations.

The low $K_{0}$ value adopted for the reworked soil $(0 \cdot 70)$ has no effect on results. The permeability of the natural soil is expected to be low because of its high plasticity. A value $k=10^{-8} \mathrm{~cm} / \mathrm{s}$ was selected in calculations. However, it turned out not to be a significant parameter because excess pore water pressures occur in rather small soil volumes, concentrated below the piles' tips. Table 2 collects all of the adopted parameters.

\section{Simulation of construction phases}

Boundary conditions applied on the rectangular prism of soil were: zero horizontal displacements in the vertical surfaces and zero displacements in the basal lower surface of the foundation soil prism. Hydrostatic pore water pressures, consistent with the water table $5 \mathrm{~m}$ below surface, were applied to boundaries.

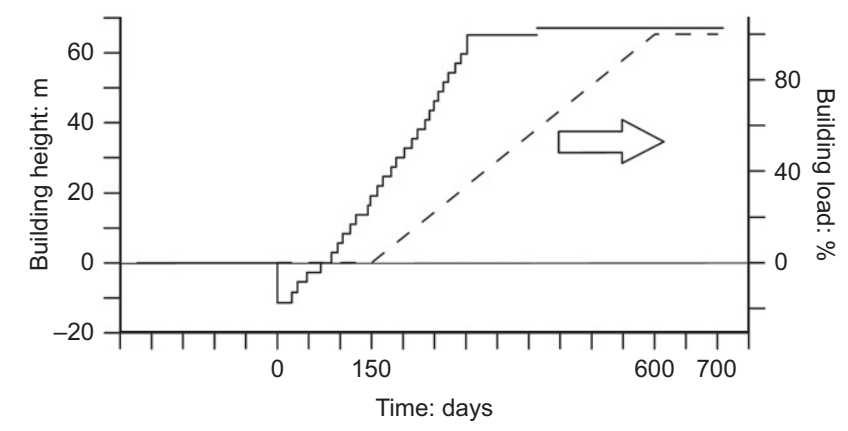

Fig. 22. Evolution of the building height (structure) and the total load applied on foundation

Once the geometry had been created, loads in the model were applied in 28 sequential stages, as follows.

(a) The first phase reproduces the state before the construction of the piles. Then, the finite elements corresponding to the building are inactive, and only one soil layer is considered whose constitutive model is the reference soil. The purpose of this phase is setting the geostatic initial stresses.

(b) The second phase simulates the construction of the eight piles (Q3, Q5, R3, R5, S3, S5, T3, and T5) by changing the constitutive model of the finite elements associated with the piles from reference soil to concrete. Furthermore, in order to consider the soil degradation below pile R3 during the construction of the widening base, the constitutive model of the finite elements in the cylindrical volume below pile R3 changes from reference soil to soft soil. This phase finalises with the activation of the interface elements representing the contact pile-soil.

(c) In phases 3 to 27, the construction of 24 floors and their columns is simulated, activating the corresponding finite elements. The average construction time for the structure of each floor was 18.75 days, leading to a construction time of the building structure of 450 days (Fig. 22). The additional dead weight associated with non-structural components (partition walls, facade, floors and ceilings) progressed at a reduced pace, as also shown in Fig. 22. Finally, the occupation of the building added the live load.

(d) The finite-element program used cannot properly model the transfer from peak (non-degraded) shear strength to residual conditions along the pile-soil interface. It is thought that the manual construction procedure induced some shearing disturbance at the soil-concrete interface, reducing the undisturbed peak friction. An approximate procedure was introduced in calculations. It was accepted that below a given relative pile-soil displacement (fixed at $5 \mathrm{~mm}$; changing it to $10 \mathrm{~mm}$ had very limited effects on results) the non-degraded properties of the contact are activated. Beyond this threshold the contact follows residual conditions.

(e) After construction of the building, a consolidation phase lasting 100 days was applied. This phase also includes the possible degradation of the pile-soil contact.

The numerical model does not include the construction of the reinforcement crutched piles, 'supporting' pile R3, because these piles were installed shortly before the collapse and most of the settlements had already occurred.

Table 6 summarises the time intervals for the construction and consolidation phases. The total load was applied in 24 
Table 6. Time intervals for the main events considered in the model

\begin{tabular}{l|r}
\hline Event & Time interval: days \\
\hline $\begin{array}{l}\text { Construction of piles (second phase) } \\
\text { Construction and loading of } \\
\text { building (third to 27th phase) }\end{array}$ & $0-150$ \\
Additional time for consolidation & $600-600$ \\
\hline
\end{tabular}

steps, after foundation installation. This phase lasted 450 days. Calculations were made always in a coupled hydro-mechanical manner. In other words, no distinction between undrained and drained analysis was made. Then, an additional consolidation time of 100 days, at constant total stresses, was considered.

\section{DISCUSSION OF RESULTS}

This section compares the data of settlement monitoring and the results obtained from the finite-element method simulation. In general, the computed evolutions of the pile settlements reproduce quite satisfactorily the corresponding recorded evolutions. Particularly accurate (Fig. 23) are the results of the evolution of the settlement of piles R3 (no enlarged base) and S3 (the column where the first symptoms of column exhaustion were observed: Fig. 9(a)).

However, Fig. 24 shows some discrepancies between calculations and measurements of the final settlement of piles R5 and S5. The reasons for this discrepancy could be associated with deviations in the geomechanical properties of the soil below these piles (geometry of the enlarged bases) or

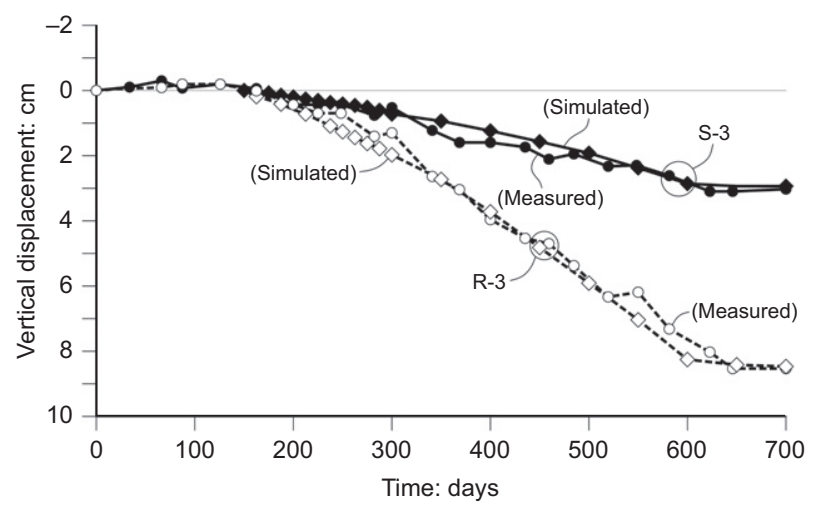

Fig. 23. Measured and computed evolutions of displacements for piles R3 and S3

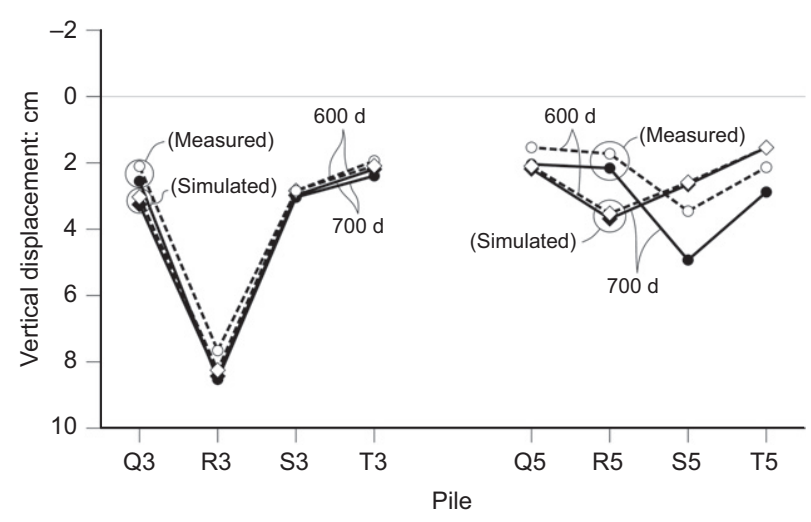

Fig. 24. Measured and computed distributions of pile displacements at 600 days (floor 24) and 700 days (100 days after floor 24) unknown degradation of the soil below these piles resulting from the construction of the reinforcement 'crutches' piles.

Figure 25 presents the simulated settlement-load curves of all piles. Results show that pile R3 (no enlarged base) reached its ultimate capacity at a rather small load. Other piles can withstand larger loads, except piles T3 and T5, which have smaller footing enlargements. Results shown in Fig. 25 indicate that pile R3 failed because of the lack of bearing support at the base. The calculated limiting load for R3 is around $3500 \mathrm{kN}$ for a settlement of $0.035 \mathrm{~m}$. It is in a state of failure and settlements increase fast for small load increments.

For comparison purposes, the loads on each pile have also been computed using a loading factor that represents the proportion of the load that withstands each pile assuming a uniform load distribution. This factor quantifies the afferent floor area contributing to loading the piles. Figs 26 and 27 show a comparison of loads on piles R3-S3 and R3-Q3 computed using proportional loading factors and the loads obtained by numerical simulation, which incorporates the interaction between the building structure and the pile foundation response.

Because of the reduced bearing capacity of pile R3 due to the lack of footing widening and the soft soil under the base, the structure of the building transferred additional load to piles connected with pile R3. A comparison of the theoretical pile loads computed with proportional load factors and the results of the numerical model in the vicinity of pile R 3 along axis 3 is summarised as follows.

(a) The column over pile R3 experiences a load decrease of $60 \%$ compared with the load obtained using the corresponding loading factor.

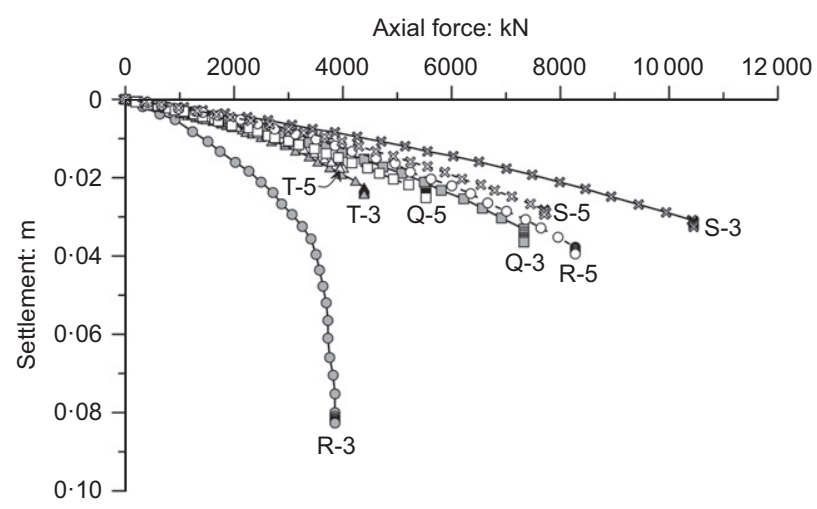

Fig. 25. Calculated displacement-force curves of piles

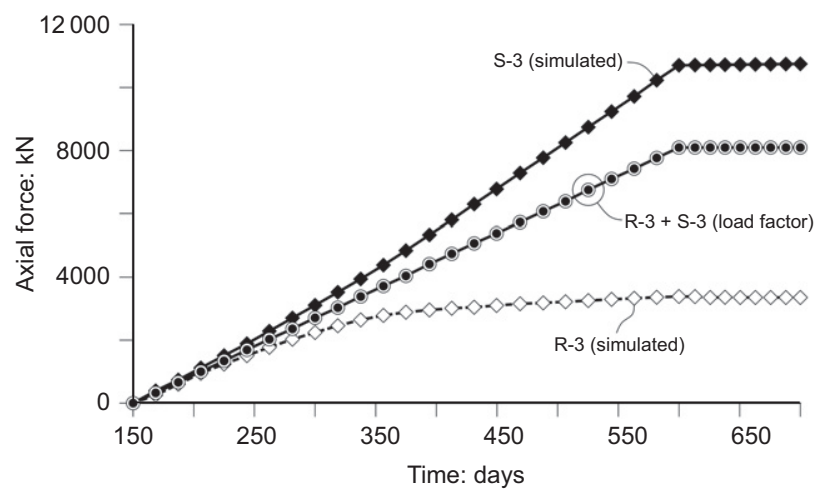

Fig. 26. Evolution of the forces applied to the piles R3 and S3, compared with the corresponding forces obtained using a loading factor (since the loading factor for pile R3 is the same as the factor for pile S3, the two evolution curves coincide) 
(b) The column founded on pile S3 experiences a load increase of $28 \%$ compared with the load obtained using the corresponding loading factor.

(c) The column founded on pile Q3 experiences a load increase of $32 \%$ compared with the load obtained using the corresponding loading factor.

Note also (Fig. 25) that column S3 receives the highest load, estimated as $10400 \mathrm{kN}$. The additional load transmission on column S3, and the deficit in the structural capacity of this column, explains the collapse of column S3 (Yamin, 2014). The collapse of column S3 led to the collapse of the entire building.

The model also provided an additional insight into the performance of the pile foundations. Soil consolidation had a minor effect on the development of settlements. This is a consequence of the small extent of soil volumes which experienced a significant excess pore pressures during building construction. Fig. 28 shows the calculated excess pore pressures in a vertical section along axis 3 when the building reached floor 24. The group effect is very much reduced owing to the long distance between piles $(7.5$ to $8.3 \mathrm{~m})$. Excess pore pressures are small along the pile shafts and concentrate below the base of each individual pile. Consolidation was relatively fast despite the low permeability adopted for the soil $\left(k=10^{-8} \mathrm{~cm} / \mathrm{s}\right.$ for the undisturbed soil).

The approximate procedure introduced to account for the degradation of the shear strength along the pile shafts contributed to understanding the performance of piles. Figs 29 and 30 show calculated yielding points in elements of the finite-element mesh at two instants of the loading process, when the building reached floors 12 and 24,

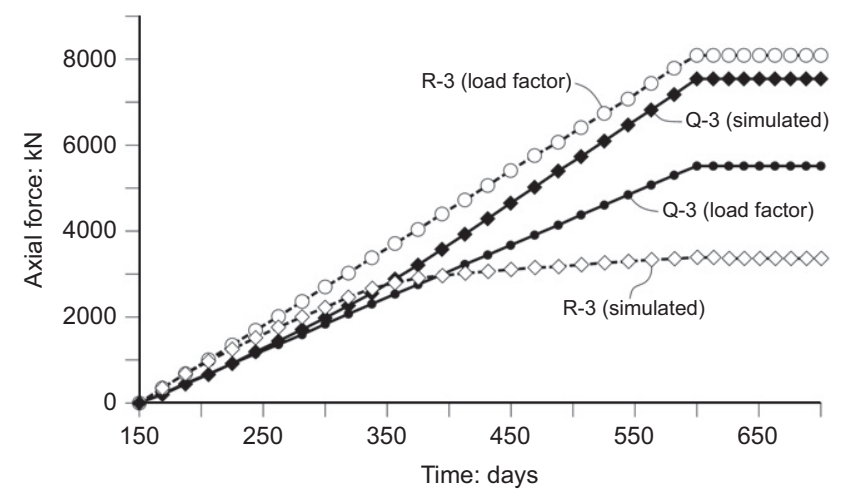

Fig. 27. Evolution of the forces applied to the piles R3 and Q3 compared with the corresponding forces obtained using a load factor

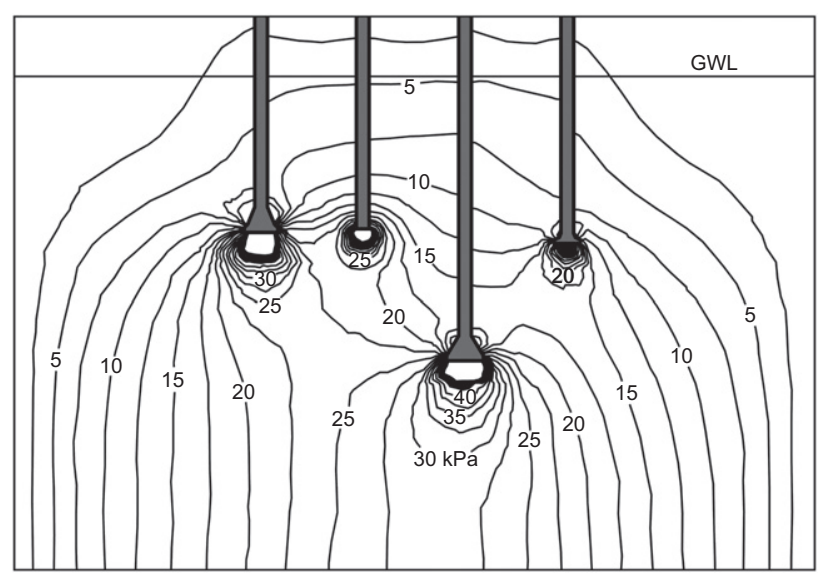

Fig. 28. Distribution of excess pore water pressures on the vertical plane through the centres of piles Q3, R3, S3 and T3 at 600 days (floor 24) respectively. In the first case (Fig. 29) shear yielding is massive in pile R3. The upper parts of all piles had reached a degraded strength and soil under the enlarged bases also experience some yielding.

When the total building load is applied (Fig. 30) shear yielding along the shafts of all piles extends downwards. The longest piles (S3, S5) maintain about 3/4 of the pile shaft within the elastic range.

\section{SUMMARY, CONCLUSIONS AND \\ LESSONS LEARNED}

This paper analyses the causes behind the collapse of a 24-storey high building located in Medellín, Colombia.

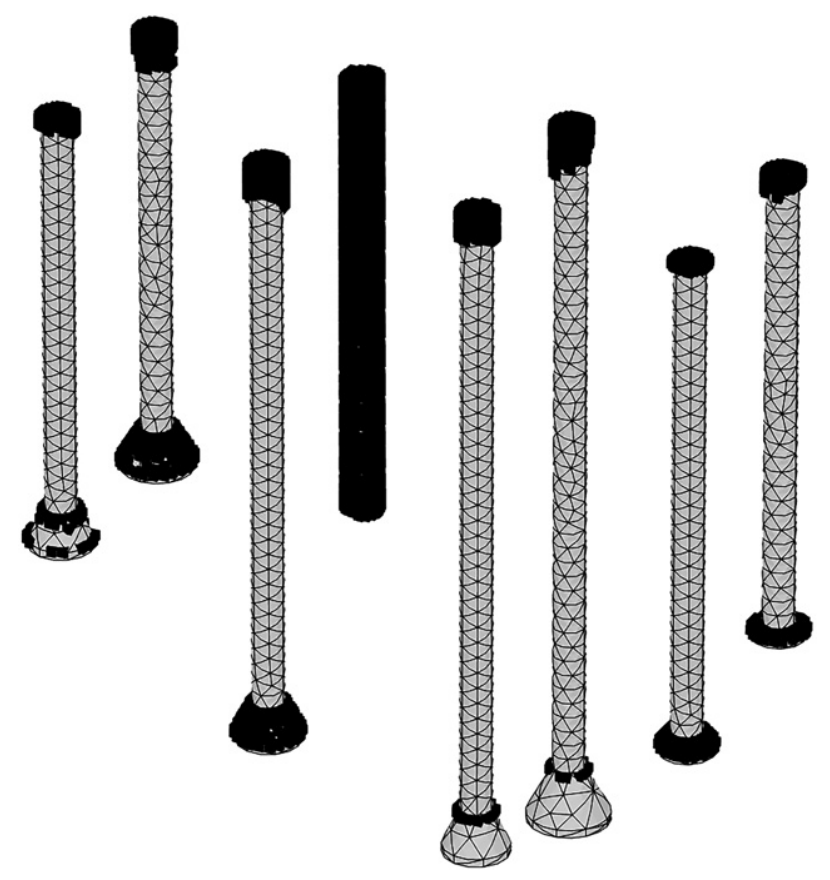

Fig. 29. Distribution of failure points on the pile-soil interfaces of piles Q3, R3, S3, T3, Q5, R5, S5 and T5 at 375 days (floor 12)

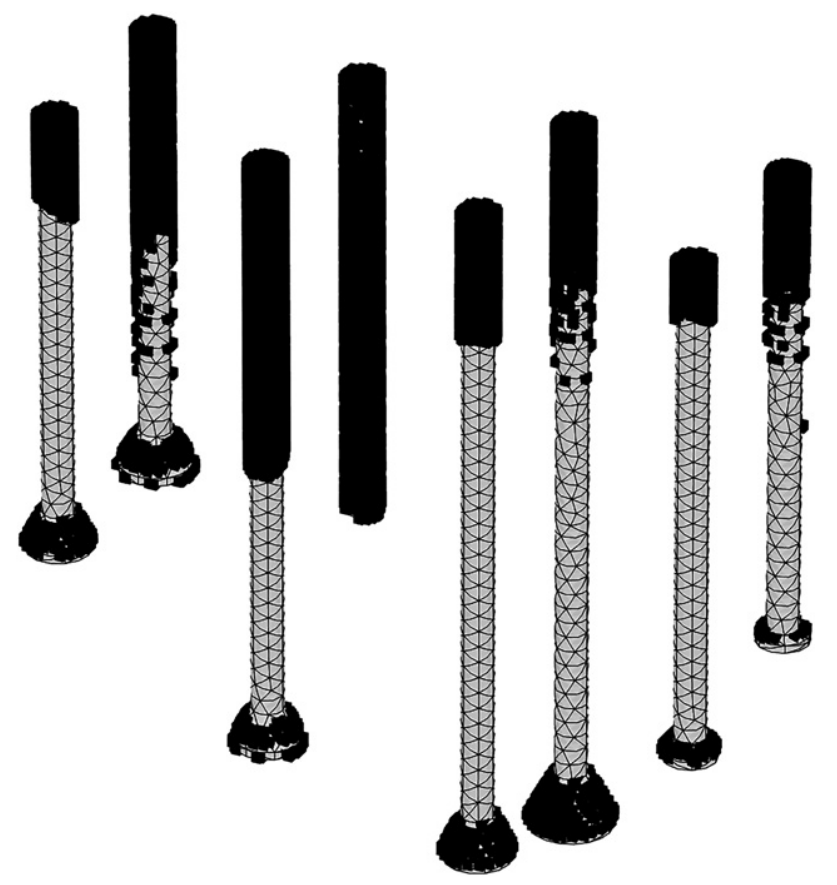

Fig. 30. Distribution of failure points on the pile-soil interfaces of piles Q3, R3, S3, T3, Q5, R5, S5 and T5 at 600 days (floor 24) 
Isolated caisson piles, a characteristic foundation procedure used in the region, supported the building columns. The soil is a heterogeneous residual saprolitic soil of medium stiffness and high plasticity.

The paper describes the geotechnical characteristics of the soil, and the elastoplastic model used in calculations. Model parameters were approximated by laboratory oedometric and triaxial consolidated undrained laboratory tests on undisturbed samples recovered in a large-diameter investigation caisson excavated after failure.

The recorded settlements of piles during construction provided most valuable data to interpret the interaction between the structure and the piled foundation. The settlement history of the piles provided useful data, which supplied the necessary reference when different hypotheses were advanced to interpret the recorded settlements. The results described in this paper are a fraction of the set of calculations performed. Time effects were investigated by means of a viscous soil model and by modifying the soil permeability. The effect of building stiffness and its possible degradation in time, due to the damage experienced by the structure, was also investigated by a few alternatives, which related stiffness with calculated differential settlements. It was realised that the main controlling factor was the actual history of loading, as described in this paper.

The piled foundation built was rather dissimilar from the intended design because of differences in pile length and the diameter of the enlarged base. The most significant feature, however, was the foundation of one of the building columns (R3), which was supported by a short pile (compared with the rest of piles) resting on a softer material and without base enlargement. This singularity was a consequence of the difficulties experienced during handmade excavation of the pile.

Because of the failure of the pile R3, the load transfer among pile R3 and neighbouring piles was very significant. It explains the substantial increase in load transmitted to the rigid S3 pile. The column supported by this pile experienced a $28 \%$ increase in vertical load (according to model results), which resulted in its failure. In fact, observations prior to the building failure showed the extreme damage experienced by the building column supported by the $\mathrm{S} 3$ pile.

Differences in the single pile foundations and the role of the building structure, distributing the load among piles, ultimately explain well the recorded pile settlements. Model results, computed for a uniform average soil, suggest that soil heterogeneity played a reduced role in this case. Some discrepancies between calculated and measured settlements could probably be explained by local heterogeneities, but the developed model captures the global picture.

The set of piles behaved essentially as isolated piles. No significant group action was identified. Pore pressures concentrated on pile tips in small soil volumes, which facilitated a relatively rapid consolidation despite the clayey nature of the foundation soil.

The transmission of shear loading between piles and surrounding soil was also investigated. Foundation soils along pile lengths are medium- to high-plasticity clay soils $\left(w_{1}=40 \%\right.$ to $\left.80 \%\right)$ and degradation in shearing of the strength available at the pile-soil interface is expected. The ultimate residual strength available in this interface was approximated by a ring shear test on the soil recovered in an exploratory well. A procedure was implemented in the calculation of the pile reaction to approximate the effects of transition from peak to residual strength when piles settle.

The collapse of Space building teaches a few lessons. An obvious one, in the case of faulty construction of a given pile, is to provide for additional supporting piles before any loading is applied. The case also shows the risks of modifying pile lengths and, in general, the geometry specified in the project. Pile dimensions in the case of the Space building were a consequence of heterogeneous soil conditions and the particular pile construction procedure. The consequences of introducing changes should be immediately evaluated by the responsible geotechnical and structural engineers.

The most relevant lesson from this dramatic failure, however, is the need to provide structural redundancy to the foundation design. Ideally, this redundancy should be provided at the foundation level to minimise the development of differential settlements and their effect on the supported structure. The Space foundation design (single piles per column at large inter-axis distances $-7.5 \times 8.3 \mathrm{~m}$ ) did not provide a possibility of reducing differential settlements among columns. In fact, this comment is extended to horizontal displacements and rotations. The consequence, when the faulty pile reached rapidly its failure load, was the transfer of interaction loads and moments to the structure.

The Space reinforced concrete structure experienced an 'optimisation' process after its initial design, to reduce to the minimum, or even less, the dimensions and reinforcement required in the local construction codes. The two circumstances: a low structural safety and the column loads re-distribution, because of the foundation differential settlements, were capable of exhausting the compression resistance of the most heavily loaded column. It is believed that the collapse of this column and the subsequent dynamic overload, following the column collapse, led to the entire building collapse.

A stiff structural grid connecting the pile caps could most probably have saved the building. This is a good solution in the case of highly variable soil conditions and traditional pile construction practices, which cannot guarantee a homogeneous stiffness of all piles. There are, certainly, other alternatives if mechanised construction procedures are employed.

\section{REFERENCES}

Berezantzev, V. G., Khristoforov, V. \& Golubkov, V. (1961). Load bearing capacity and deformation of piled foundations. In Proceedings of the 5th international conference on soil mechanics and foundation engineering, vol. 2, pp. 11-15. Paris, France: Dunod.

Brinkgreve, R. B. J., Kumarswamy, S. \& Swolfs, W. M. (2016). Plaxis 2016. Delft, the Netherlands: Plaxis bv.

Cavalcante, E. H., Danzinger, F. A. B., Giacheti, H. L., Coutinho, R. Q., Souza, A., Kormann, A. C. M., Belincanta, A., Pinto, C. S., Costa Branco, C. J. M., Ferreira, C. V., Carvalho, D., Marinho, A. M., Cintra, J. C. A., Dourado, K. C. A., Moraes, L. S., Albuquerque Filho, L. H., Almeida, M. S. S., Gutierrez, N. H. M., Albuquerque, P. J. R., Chamecki, P. R., Cunha, R. P., Teixeira, R. S., Menezes, S. M. \& Lacerda, W. A. (2007). Campos experimentais brasileiros. Revista Luso-Brasileira de Geotecnia 111, 99-205 (in Portuguese).

Mendoza, C. C. (2013). Experimental and numerical behaviour of deep foundations made up by anker alluvial type piles founded in a porous soil of federal district. $\mathrm{PhD}$ thesis, University of Brasilia, Brasilia, DF, Brazil (in Portuguese).

Schanz, T., Vermeer, P. A. \& Bonnier, P. G. (1999). The hardening soil model: formulation and verification. In Beyond 2000 in computational geotechnics: ten years of Plaxis International (ed. R. B. J. Brinkgreve), pp. 281-296. Amsterdam, the Netherlands: Balkema.

Yamin, L. (2014). Technical concept about the more relevant causes of the collapse of the space building. Universidad de Los Andes, Bogotá, Colombia. See http://www.medellin.gov.co/irj/go/km/ docs/pccdesign/SubportaldelCiudadano_2/PlandeDesarrollo_0_ 15/Noticias/Shared\%20Content/Documentos/2014/Uniandes_ Informe-Final-Fase3-SPACE-Resumen.pdf (accessed 05/03/ 2018). 